Peramo, Juan Carlos. Paraísos fiscales, riqueza offshore y evasión fiscal. Una estimación para España (1980-2013).

\title{
PARAÍSOS FISCALES, RIQUEZA OFFSHORE Y EVASIÓN FISCAL. UNA ESTIMACIÓN PARA ESPAÑA (1980-2013) ${ }^{1}$
}

\author{
TAX HAVENS, OFFSHORE WEALTH AND TAX EVASION. AN \\ ESTIMATE FOR SPAIN (1980-2013)
}

\author{
JUAN CARLOS PERAMO \\ Universidad Complutense de Madrid \\ jperamo@ucm.es
}

Fecha de recepción: marzo 2016

Fecha de aceptación: abril 2016

\begin{abstract}
RESUMEN
La problemática de los paraísos fiscales es un fenómeno cada vez más relevante en el funcionamiento de la economía mundial y está estrechamente relacionado con las crisis financieras y el aumento de la desigualdad. No obstante, existe escasa literatura que cuantifique el problema. El propósito de este trabajo es el de elaborar una propuesta metodológica que sirva de base para la ampliación del estudio de este tema, tan poco estudiado y del que aún se desconoce demasiado, pese a su importancia y presencia en la actualidad. Para ello se recopila la terminología empleada en la literatura relacionada con los paraísos fiscales y la riqueza offshore así como la metodología empleada en algunas estimaciones que cuantifican el problema. A partir de dicha recopilación se propone una estimación para España en el periodo 1980-2013, de la riqueza radicada en paraísos fiscales (offshore) y su repercusión sobre los ingresos fiscales del país, empleada por Zucman para el caso de Francia. Los resultados arrojan un incremento de la riqueza offshore durante todo el periodo y una pérdida de ingresos tributarios acumulados para el país de 116.000 millones de euros.
\end{abstract}

PALABRAS CLAVE: paraísos fiscales, globalización financiera, opacidad, fiscalidad, evasión fiscal.

\section{ABSTRACT}

The problematic of tax havens is an increasingly relevant phenomenon in the functioning of the world economy and is closely related to the financial crisis and rising inequality. However, there is little literature to quantify the problem. The purpose of this work is to develop a methodology as a basis for extending the study of this subject, so little studied and still too unknown, despite its importance and presence nowadays. For this, the terminology used in the literature on tax havens and offshore wealth as well as the methodology used in some estimates that quantify the problem is collected. From this collection an estimate for Spain is proposed for the 1980-2013 period, wealth based in tax havens (offshore) and its impact on tax

\footnotetext{
${ }^{1}$ El presente trabajo se complementa con un apéndice metodológico y otro electrónico disponibles en: https://drive.google.com/open?id=0B5F1oFIq0vVNTGRYVWF1VEgyNnc. 
Peramo, Juan Carlos. Paraísos fiscales, riqueza offshore y evasión fiscal. Una estimación para España (1980-2013).

revenues, applied by Zucman to the case of France. The results show an increase in offshore wealth throughout the period and a loss of tax revenue accumulated for the country of 116.000 million euros.

KEY WORDS: tax havens, financial globalization, opacity, taxation, tax evasion.

JEL: F02, F32, H26, H87.

\section{INTRODUCCIÓN}

El fenómeno de la globalización, y en especial de la globalización financiera, ha contribuido al desarrollo de la interconexión entre países. Desde las crisis del petróleo de los años setenta y la crisis de la deuda, el consenso neoliberal ha acelerado los procesos de liberalización en la movilidad de capitales, eliminando casi la totalidad de las barreras a su circulación y fomentando la competencia entre países por conseguir su atracción. Esto ha llevado a la pérdida progresiva de control e información sobre los capitales por parte de los Estados. Los agentes han adquirido, sobre todo los que disponen de más recursos, la posibilidad de mover sus activos, más allá de las fronteras de su país de residencia hacia territorios donde pueden ocultarlo a su hacienda pública (convirtiéndolos de esta manera en riqueza offshore), para así evitar en la mayoría de los casos, bien que se descubra la existencia de una actividad ilegal, bien que se graven los rendimientos o el patrimonio provenientes de una actividad legal y se tribute por ella (evasión fiscal). En este contexto surgen los paraísos fiscales, que pese a la ausencia de una definición consensuada, debido a la complejidad del problema que representa, básicamente significan territorios o jurisdicciones especializados en atraer esos activos cuyos poseedores no quieren declarar su procedencia y/o tributar en el país de origen, ya que la opacidad existente en aquellos permite no proveer información a los haciendas públicas del país de procedencia, sin importar el posible origen lícito o ilícito de los mismos.

El presente trabajo trata de servir como base metodológica para abordar el estudio de la problemática de los paraísos fiscales desde un enfoque crítico, así como recopilar las distintas estimaciones que tratan de cuantificar el problema con el fin de comparar sus resultados y las metodologías que emplean. A partir de dicha compilación, teniendo en cuenta las fortalezas y las debilidades de cada una, se propone una estimación para cuantificar tanto la riqueza offshore procedente de España, como la evasión fiscal que esta genera para el periodo 1980-2013. El trabajo se encuentra enmarcado en el estudio de la fiscalidad internacional y se concentra en la problemática sobre la acumulación de riqueza por parte de individuos a través de estas plataformas y la evasión fiscal que practican en la mayoría de los casos.

La justificación del presente trabajo parte de la consideración de que el paso previo a una actuación de política económica en un asunto tan relevante a nivel internacional y que inmiscuye a tantos actores, es la cuantificación del problema para medir su importancia e impacto, y es que:

"No hay ningún avance posible sin una estimación calculada de la amplitud del fraude. Sólo basándonos en semejante evaluación, por imperfecta que sea, es posible imponer sanciones y seguir la realidad de los avances en la lucha contra esta lacra" (Zucman, 2013a: 11). 
Peramo, Juan Carlos. Paraísos fiscales, riqueza offshore y evasión fiscal. Una estimación para España (1980-2013).

Además de cuantificar el fenómeno, este trabajo revisa y analiza las distintas concepciones, acepciones y terminologías utilizadas por los autores especializados para abordar y situar en el contexto las distintas aristas de la temática. Las preguntas de investigación que lo conducen serían las siguientes: ¿Existe literatura estructurada sobre paraísos fiscales y evasión fiscal a través de estos? ¿Son consistentes los intentos de cuantificar aunque sea de manera aproximada la magnitud del problema? ¿Difieren de manera significativa? ¿Los resultados muestran un aumento? ¿Qué dimensión tiene la riqueza radicada offshore, en un país como España y qué supone en pérdida de recaudación fiscal?

Partimos de la hipótesis de que debido a la opacidad existente en los territorios conocidos como paraísos fiscales y así como por parte de las entidades que operan en ellos, es posible hacer una valoración general del fenómeno offshore, pero resulta imposible poder separar de forma fehaciente las cantidades trasladadas desde cada uno de los países. Consecuencia de las divergencias conceptuales, de la opacidad en las fuentes, el empleo de la metodología para la cuantificación del problema diferirá tanto en los cálculos como en los resultados obtenidos. No obstante, debería poderse observar un aumento sostenido en el tiempo debido al proceso de financiarización de la economía en las últimas décadas.

En este sentido, tras este apartado introductorio se situará la problemática de los paraísos fiscales, y se presentarán la terminología y las definiciones que rodean a este fenómeno. A continuación, se analiza más en detalle y se cuantifican los aspectos que centran el presente trabajo, la riqueza offshore (esto es, el traslado de activos fuera del país de origen sin comunicación a las autoridades). Para ello, se comparan distintas estimaciones a escala global de diferentes autores, para conocer de una manera aproximada la magnitud del problema. Después se presenta la estimación propia aplicando una metodología refutada al caso de España para el periodo 1980-2013. Finalmente se exponen las conclusiones.

\section{LA PROBLEMÁTICA DE LOS PARAÍSOS FISCALES}

La trascendencia de los paraísos fiscales en la economía internacional no se limita al plano de la evasión tributaria y la delincuencia financiera, sino que además tienen relación directa con la gestación de las crisis financieras al suponer elementos clave en la configuración de la economía mundial financiarizada. Por otra parte, son un fenómeno que agudiza las desigualdades y la pobreza, y distorsionan la realidad de los desequilibrios macroeconómicos realmente existentes a nivel mundial. Además, representan una amenaza para la sostenibilidad de la financiación de los estados desarrollados y dificultan (si no imposibilitan) el establecimiento de sistemas impositivos estables en los países en vías de desarrollo, así como socavan las democracias y ponen en riesgo la justicia social, al permitir y proteger las actividades ilícitas ya sean las relacionadas con la delincuencia financiera o con el blanqueo de dinero de origen criminal.

A continuación pondremos en contexto de estos debates la problemática de los paraísos fiscales. 
Peramo, Juan Carlos. Paraísos fiscales, riqueza offshore y evasión fiscal. Una estimación para España (1980-2013).

\subsection{Elemento clave de la economía financiarizada}

Los paraísos fiscales suponen una pieza clave en el puzle de las finanzas a nivel mundial, la cual ha experimentado un proceso de financiarización desde los años setenta. Por financiarización entendemos la definición de Lapavitsas (2011: 611612):

"a systemic transformation of mature capitalist economies that comprises three fundamental elements: first, large non-financial corporations have reduced their reliance on bank loans and have acquired financial capacities; second, banks have expanded their mediating activities in financial markets as well as lending to households; third, households have become increasingly involved in the realm of finance both as debtors and as asset holders. The crisis of 2007-9 is directly related to these developments".

Esta triple transformación coincide con el desarrollo de los paraísos fiscales: en primer lugar, las empresas han aumentado su capacidad de localizar de manera ficticia las bases imponibles de sus beneficios en territorios donde tributan menos, bien mediante localización vinculada a exenciones y rebajas fiscales asociadas a fenómenos de deslocalización en paraísos fiscales (profit shifting), explotando las leyes bilaterales entre países (treaty shopping), mediante técnicas de manipulación de los precios de transferencia en las operaciones intrafirma, o bien, mediante préstamos intragrupo. Estas técnicas de elusión fiscal, han proporcionado un crecimiento de los beneficios radicados offshore de manera significativa desde los años ochenta (para un ejemplo de las transnacionales estadounidense véase gráfico 1) y es el objeto de estudio de numerosas investigaciones (Clausing, 2009; Karikari, 2014; Oxfam, 2015; entre otros).

\section{Gráfico 1}

The Share of Tax Havens in US Corporate Profits Made Abroad

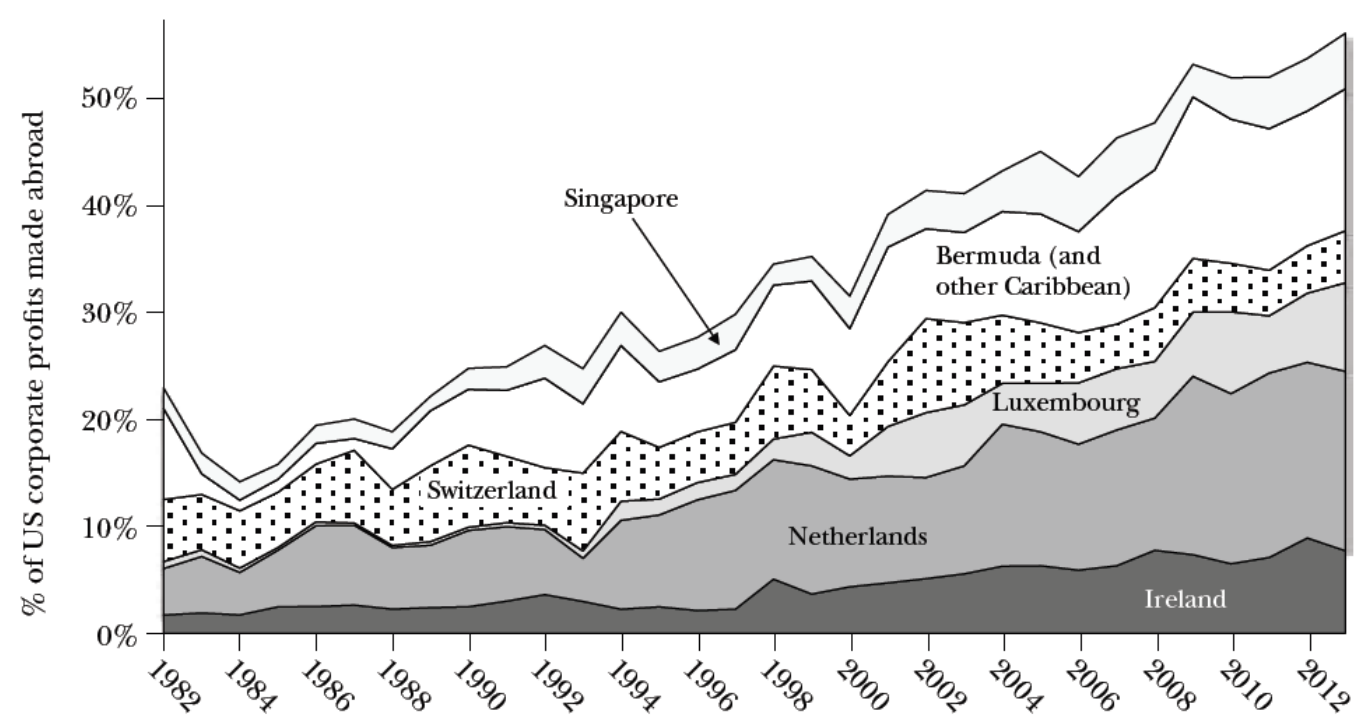

Fuente: Zucman, 2014: 128

Por otro lado, la gran banca privada se ha especializado en las actividades de los paraísos fiscales abriendo sucursales en estos territorios, proveyendo servicios de asesoría sobre inversión al igual que los bancos onshore, pero también oportunidades para evadir impuestos (Zucman, 2013b: 1327). Una de las actividades 
Peramo, Juan Carlos. Paraísos fiscales, riqueza offshore y evasión fiscal. Una estimación para España (1980-2013).

más importantes que la banca privada global lleva a cabo aprovechando la opacidad de los paraísos fiscales son los fondos de cobertura o hedge funds. En 2010, más del $60 \%$ de los hedge funds estaban localizados en paraísos fiscales (un $37 \%$ en las Islas Caimán y un $27 \%$ en Delaware, Estados Unidos). Su falta de regulación y exceso de apalancamiento hacen que sean un instrumento directamente relacionado con la gestación de crisis financieras (Garzón, 2011: 146-147). El secreto bancario es un elemento clave en la opacidad y desregulación que otorga discreción y reserva profesional a los bancos y sus empleados para no revelar el verdadero propietario de las cuentas o activos materiales (ibíd.: 144) lo que permite a las empresas e individuos utilizar los paraísos fiscales sin represalias legales.

Y tercero, los individuos con más activos han aumentado su capacidad de trasladarlos hacia paraísos fiscales para ocultarlos y/o evadir impuestos:

"The system of globalised finance exploiting offshore centres has essentially functioned as a means of low-cost financial intermediation for those fortunate enough to have acces to it." (Picciotto, 2007: 13).

Este último aspecto será el que centre el presente trabajo. Por tanto, los paraísos fiscales son una pieza clave en la configuración de la economía financiarizada y además, "están en el centro de la crisis financiera" (Zucman, 2013a) y son una parte fundamental a la hora de comprender su gestación: "they were one of the most important actors precipitating it" (Palan, Murphy y Chavagneux, 2013: 2).

\subsection{Crisis de recaudación en las economías avanzadas}

La existencia de paraísos fiscales tiene repercusión directa en la desigualdad tanto en el interior de los países como a nivel internacional entre distintas zonas geográficas. En el plano interno de un país, los paraísos "contribuye[n] a que la desigualdad de ingresos se esté disparando y a que los mecanismos de redistribución del Estado pierdan eficacia" y tienen una "importancia vital [...] sobre el nivel y calidad de vida de las sociedades modernas" (Garzón, 2011: 149-151). Debido a la libre movilidad de capitales existente desde la desregulación financiera, los Estados temen aumentar la tasación al capital, debido a la potencial fuga masiva de su territorio. Además, los capitales tienen más facilidad para radicarse offshore que las rentas provenientes del trabajo, por lo que la financiación del grueso del Estado recae en estas últimas. De esta manera, la desigualdad ya existente aumenta por vía de la carga fiscal. Vigueras (2005) afirma que de esta manera, los paraísos fiscales "socavan las democracias al ejercer fuerte presión sobre los estados condicionando las políticas fiscales y económicas".

\subsection{Desigualdad y desarrollo}

En cuanto a la desigualdad a nivel internacional, la evasión fiscal relacionada con paraísos fiscales supone un problema mayor para los países en desarrollo: "Tax havens [...] may play an even greater role in shaping the lives of those who live in developing countries." (Palan et. al., 2013: 172). Por ejemplo, los activos que los residentes de África poseen en Suiza supondrían 120.000 millones de euros, más que los que poseerían los residentes estadounidenses, cuando su PIB es siete veces mayor que el continente africano (Zucman, 2013a: 46). El estudio del autor francés, como veremos más adelante, muestra como el "mundo rico" sería un acreedor neto si se contabilizaran los flujos no registrados relacionados con los 
Peramo, Juan Carlos. Paraísos fiscales, riqueza offshore y evasión fiscal. Una estimación para España (1980-2013).

paraísos fiscales. Por tanto, la problemática del los paraisos fiscales y la riqueza offshore son elementos muy importantes en los estudios de desarrollo:

"This early research led us to notice that - contrary to the basic assumptions of development economics - there were very large gross and net flows from the developing world to OECD countries: not only in the form of demand for reserve assets like currency and gold, but also for ordinary financial assets." (Henry, 2012: 14).

Para los países en desarrollo, la mayor fuente de problemas proviene de la fuga de capitales. Se trata de un problema fundamental para la recaudación de sus haciendas públicas, mayor que para la de los países desarrollados: "Such losses of tax revenues are far from limited to rich OECD countries. Indeed, developing countries suffer far more due to capital flight which is facilitated and encouraged by the offshore system." (Picciotto, 2007: 12)2. Cobham (2005) calcula unas pérdidas de recaudación fiscal de 385 mil millones de dólares anuales para el conjunto de países en desarrollo. Por tanto, los paraísos fiscales tienen repercusión directa en los países en desarrollo agravando los problemas de sostenimiento de la deuda, de deterioro de los términos de intercambio y de declive de la ayuda al desarrollo (Oxfam, 2000).

\section{TERMINOLOGÍA: CONCEPTOS Y DEFINICIONES}

Los paraísos fiscales son aquellos países en los que los residentes extranjeros, empresas o personas ricas colocan su dinero para evitar pagar impuestos en sus territorios de origen (Chavegnaux y Palan, 2007: 13). El término paraíso fiscal proviene del término "tax heaven" cuya pronunciación es parecida a "tax haven" el cual es utilizado en la literatura anglosajona y cuyo significado en inglés es refugio fiscal. Algunos autores remarcan este fallo en la traducción para incidir en que se trata de:

"Un error de traducción que no es casual, ni irrelevante" ya que se da "una diferencia semántica muy importante. No es lo mismo un refugio, consecuencia de un ataque confiscatorio, que un paraíso. Es importante, porque ese error de traducción ocurre, no por casualidad tampoco, en los países donde triunfan las políticas más intervencionistas" (Lacalle, 2013).

Los primeros estudios que utilizan el término "paraíso fiscal" (paradis fiscaux/fiscal) provienen de la literatura francófona de los años setenta, década en la que el término comenzó a extenderse (véase Bouvier, 1972; Meister, 1975; Schuller, 1977; entre otros).

No obstante, el término original haven se aplicaba para designar a los puertos seguros del Caribe donde se refugiaban piratas que actuaban al margen de la Ley y otros con patentes de corso soberanas (corsarios) procedentes sobre todo de Gran Bretaña y Holanda y donde evidentemente no se pagaban impuestos (De la Torre, 2014: 162). De hecho, la mayoría de actuales territorios utilizados para pagar menos impuestos a nivel internacional son antiguos territorios de ambos países (Islas Bermudas o Antillas Holandesas respectivamente). Por tanto no es cierto que sea un error de traducción entre haven y heaven, con el fin de justificar una política "intervencionista". El análisis histórico de ambos términos muestra que se refieren a

\footnotetext{
${ }^{2}$ Para un estudio más amplio del fenómeno véase Hollingshead, 2010; Kar, Cartwright-Smith y Hollingshead, 2010; Gaggero, Rua y Gaggero, 2013; Henry, 2012, apéndice II donde provee un extenso estado del arte acerca de esta cuestión.
} 
Peramo, Juan Carlos. Paraísos fiscales, riqueza offshore y evasión fiscal. Una estimación para España (1980-2013).

la misma cosa: territorios de ultramar donde las riquezas no estaban sujetas a cumplir obligaciones con el fisco del lugar de origen. De hecho, Hines y Rice (1990) fueron los primeros en utilizar el término "fiscal paradise" que frecuentemente utilizan los autores de la Tax Justice Network (véase Murphy, 2005). Así, la literatura francófona y también la hispana ha adoptado el término "paraíso fiscal" (véase De la Torre, 2014; Vigueras, 2005, 2013; Gaggero et. al., 2013, 2013; Garzón, 2011; entre otros) quizás por tratarse de un término con una denotación más polémica y por considerarlo más adecuado para describir la problemática del fenómeno.

El término reciente para referirse a los paraísos fiscales es centro financiero extraterritorial u offshore: el Banco de Reglamentaciones Internacionales denomina a estos territorios como "centros financieros extraterritoriales" caracterizados porque sus actividades han crecido de manera espontánea y no organizada. Para la Organización para la Cooperación y el Desarrollo Económico (OCDE), se trata de una jurisdicción que no grava con impuestos a las rentas del capital o que las grava muy poco y que presenta además una de las tres características siguientes: falta de transparencia, la negativa a proporcionar información a las autoridades extranjeras y la posibilidad de crear empresas ficticias. Según el Grupo de Acción Financiera (GAFI), son "países o territorios no cooperativos" sin reglamentación en materia financiera, de cooperación administrativa internacional y de prevención, detección y represión del blanqueo de capitales (en Chavagneux y Palan, 2007: 15). Para el Foro para la Estabilidad Financiera, los centros offshore son "jurisdicciones que atraen un nivel elevado de actividad por parte de no residentes". Proponen una imposición baja, un régimen poco exigente de inscripción de las empresas, un nivel de confidencialidad de las transacciones excesivo y la imposibilidad, por parte de los residentes, de acceder a las mismas ventajas. Estos centros no buscan que las empresas a las que quieren atraer vayan a instalarse en su territorio (Guarnsey incluso lo desaconseja) (ibid, 16-17). En cuanto al Fondo Monetario Internacional (FMI) denomina a los offshore financial centers como un país o jurisdicción que ofrece servicios financieros a no residentes en una escala que es inconmensurable con el tamaño y la financiación de la economía nacional (Zoromé, 2007: 7). Y es que, "The terms offshore financial center and tax haven are significantly related, as all tax havens (with the exception of Liberia) are also offshore financial centers, although not all offshore financial centers are tax havens" (Hollingshead, 2010: 2). De hecho, algunos estudios no hacen distinción entre "paraíso fiscal" y "centro financiero offshore" (véase Kar et. al., 2010; Zucman, 2013b). Esto se debe a que los paraísos fiscales son en esencia plataformas que sirven para operar financieramente y comercialmente en los mercados mundiales, y no como mero refugio del dinero (Vigueras, 2013).

En cuanto a la terminología relacionada con la riqueza offshore, para Palan et. al. (2013: 250) el término offshore significa: "legal space that decouples the real and the legal location of a transaction with an aim to avoid some or all kind of regulation". Cuando hablemos de riqueza financiera neta, incluimos: "bank deposits, equities, bonds, and insurance contracts, net of debts" (Zucman, 2013b: 1341). Por tanto, cuando utilicemos "riqueza offshore" nos referiremos a este tipo de activos localizados o registrados en un espacio legal cuyo objetivo es evitar alguna regulación tributaria. Por otra parte, conviene diferenciar la terminología en materia fiscal que suele utilizarse a colación de los paraísos fiscales. En primer lugar, es importante la distinción entre evasión y elusión fiscal (avoidance en inglés): 
Peramo, Juan Carlos. Paraísos fiscales, riqueza offshore y evasión fiscal. Una estimación para España (1980-2013).

"Tax evasion is the illegal non-payment of tax to the government of a jurisdiction to which it is
owed by a person, company, trust or other organization who should be a taxpayer in that
place. By definition, tax evasion is ilegal - while tax avoidance is by definition does not
technically break the law (but also by definition it involves getting around the spirit of law)."
(Murphy, 2011:2).

Es decir, evasión fiscal supondría el acto de no pagar impuestos (o pagar menos) en una situación en la que si la autoridad pública dispusiera de toda la información, lo sancionaría. Por otro lado, elusión fiscal supone no ocultar la actividad al fisco sino declararla al límite de la legalidad aprovechando sus incoherencias e imperfecciones, sobre todo en el caso de transacciones internacionales, ya que "in a world that has no global tax rules, the opportunities top lay off the taxation law of one state against that of another [...] is often difficult to resist" (Palan et. al., 2013). Por último el término economía oculta (shadow economy en inglés, o más popularmente conocido como economía sumergida) incluye:

"Those economic activities and the income derived thereof that circumvent or avoid government regulation or taxation. The major component (about two thirds) is undeclared work, which refers to the wages that workers and business don't declare to avoid taxes or documentation. The rest is represented by business underreporting profits to avoid tax regulation." (Comisión Europea, 2012, Anexo 6: 6).

Es decir, la mayoría son actividades relacionadas con la economía informal en las que bien no se declaran las rentas del trabajo o se reportan menos beneficios de los reales. No obstante, los estudios relacionados con esta cuestión (véase Murphy 2012; Schneider, 2012) sirve de referencia para la Comisión Europea a la hora de proponer iniciativas en materia de lucha contra el fraude fiscal y el secreto bancario (Comisión Europea, 2013).

"Tax havens have several links with the shadow economy, although such links are difficult to demonstrate because of their very nature. It seems at least that without 'tax havens' it would be more difficult for undeclared activities and profits to be concealed to the tax authorities of EU MS through opaque legal and corporate structures." (Comisión Europea, 2012, Anexo 6: $6)$.

Estos estudios arrojan resultados muy altos y mezclan problemas de economía sumergida con riqueza radicada en paraísos fiscales. Pese a que no es el objeto de estudio delimitado al principio del presente trabajo, las alusiones a los paraísos fiscales que se realizan en los informes hacían imprescindible su inclusión para la posterior crítica. Es importante concretar el análisis y realizar la división previamente establecida entre evasión derivada de la riqueza offshore, relacionadas con la elusión fiscal y el profit shifting y de la no declaración de actividades económicas o economía sumergida (véase gráfico 2), ya que la mezcla de más de uno de estos fenómenos puede arrojar luz sobre la problemática, pero también llevar a confusión y ambigüedad. 
Peramo, Juan Carlos. Paraísos fiscales, riqueza offshore y evasión fiscal. Una estimación para España (1980-2013).

Gráfico 2

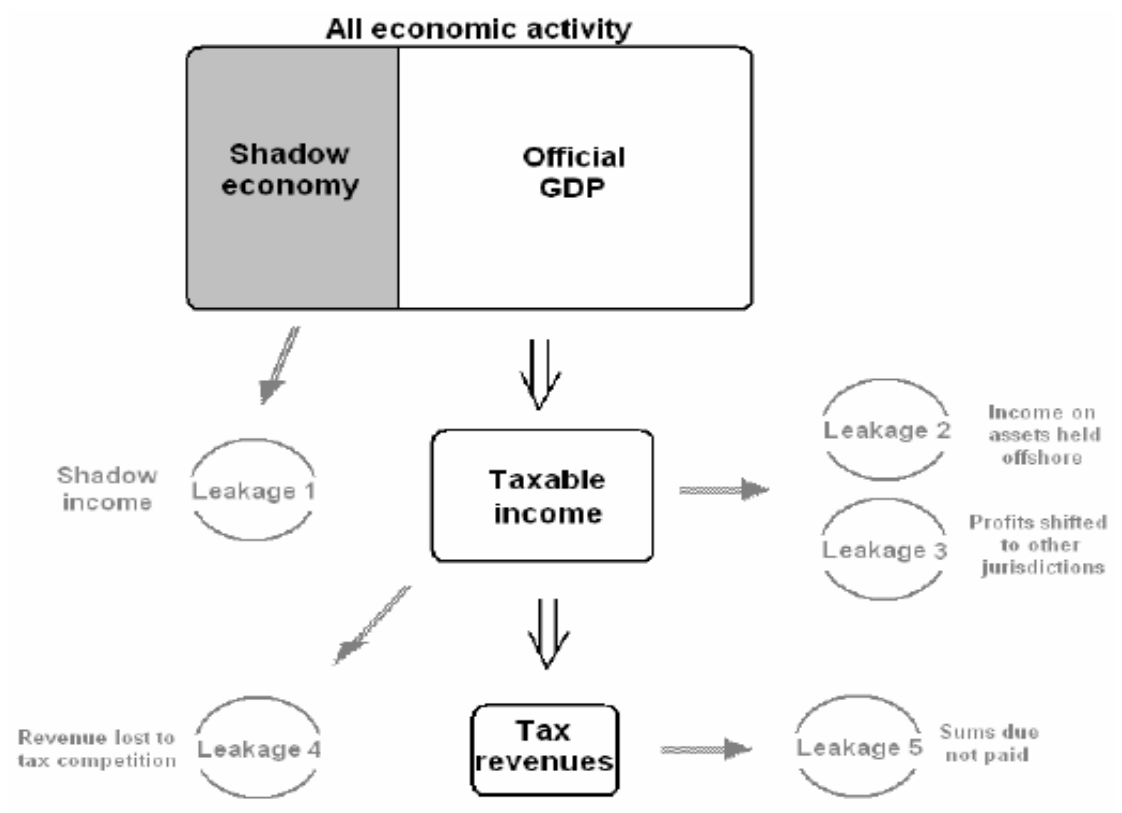

Fuente: Cobham, 2005

En el presente trabajo, se empleará el término paraíso fiscal para designar cualquier territorio en el que las leyes y la tributación existentes, permitan a las personas jurídicas extranjeras evitar pagar la totalidad o una parte de sus obligaciones fiscales en el lugar donde reside o realiza su actividad económica de facto. Por otra parte, cuando se utilicen los términos evasión fiscal, riqueza offshore y riqueza financiera neta nos referiremos a las definiciones de Henry, Palan et. al. y Zucman, anteriormente expuestas.

\section{METODOLOGÍA: ESTIMACIONES Y MÉTODOS UTILIZADOS PARA SU CUANTIFICACIÓN}

Previo al análisis más detallado de las estimaciones seleccionadas sobre riqueza offshore, destacaremos brevemente otros datos publicados con anterioridad para comprender la magnitud del problema.

Hollingshead (2010) calcula en un informe para Global Finantial Integrity, el total de depósitos privados pertenecientes a no residentes situados en las zonas de secreto bancario del mundo durante los años del periodo 1996-2009 a partir de datos bancarios del FMl y del Banco de Pagos Internacionales (BIS por sus siglas en inglés). El resultado es que estos depósitos representaban un total de 10 billones de dólares en 2009, los cuales han venido creciendo de manera sostenida a una tasa de crecimiento media del $9 \%$ anual hasta el año 2008, cuando comienzan a caer debido a la crisis financiera global (véase gráfico 3). Por otro lado los países con mayor tenencia de depósitos son en orden ascendente: Reino Unido, Islas Caimán y Estados Unidos, el cual representa más de 2 billones de dólares en 2009 (véase tabla 1). 
Peramo, Juan Carlos. Paraísos fiscales, riqueza offshore y evasión fiscal. Una estimación para España (1980-2013).

\section{Gráfico 3}

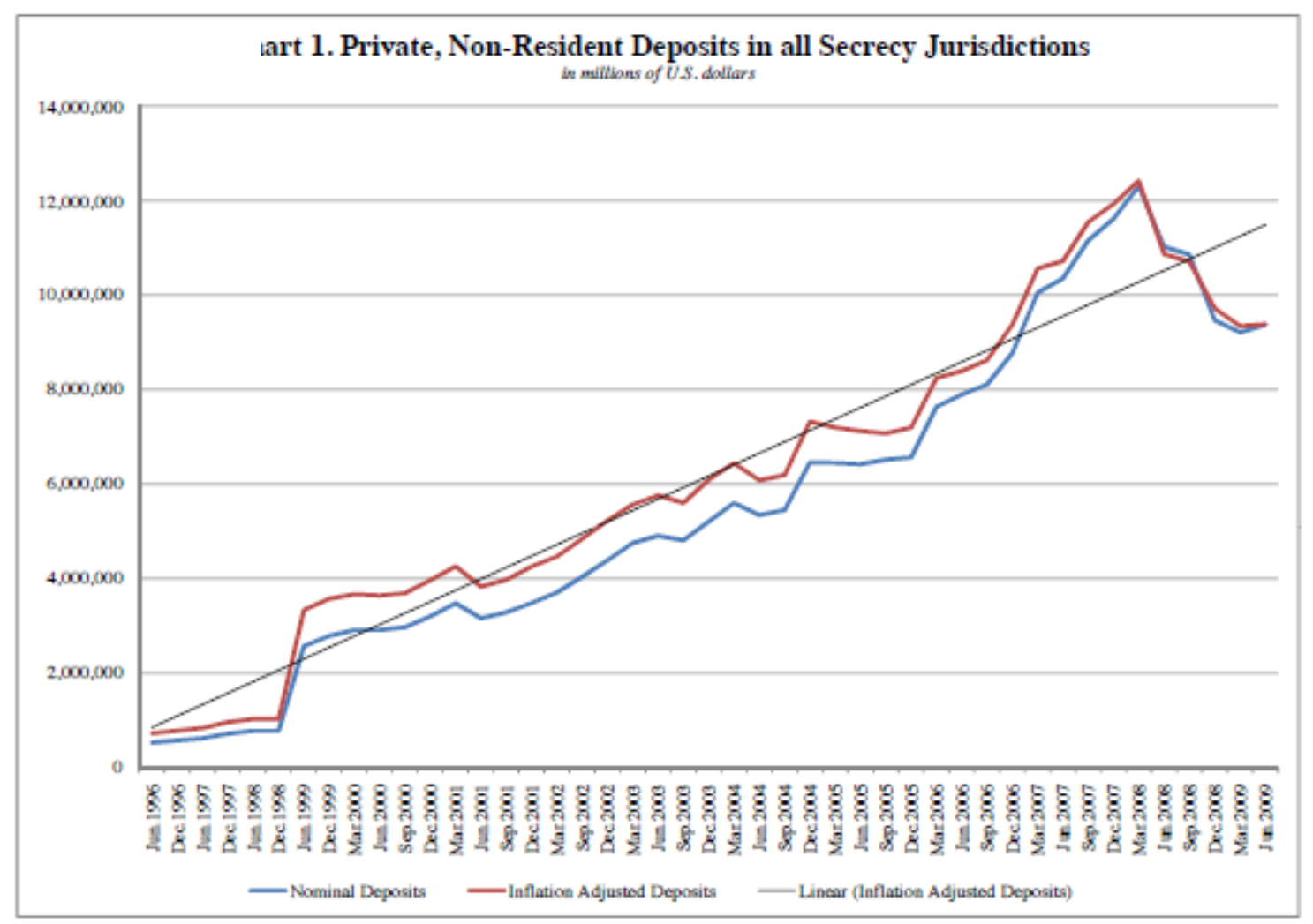

Fuente: Hollingshead, 2010: 13

Tabla 1

\begin{tabular}{|c|c|c|c|c|c|c|c|}
\hline \multirow[t]{2}{*}{ Tabla 1} & \multicolumn{6}{|c|}{ Depósitos privados de no reisdentes en las principales 10 jurisdicciones con secreto bancario } & \multirow[b]{3}{*}{ jun-09 } \\
\hline & En millones & de $\$$ & & & & & \\
\hline Ranking & Jurisdicciór & mar-08 & jun-08 & sep-08 & dic-08 & mar-09 & \\
\hline 1 & Estados Ur & $\$ 2.898 .534,87$ & $\$ 2.549 .092,88$ & $\$ 2.404 .989,86$ & $\$ 2.114 .545,84$ & $\$ 2.164 .805,09$ & $\$ 2.182 .790,93$ \\
\hline 2 & Islas Caimé & $\$ 1.736 .494,86$ & $\$ 1.515 .102,93$ & $\$ 1.483 .148,13$ & $\$ 1.684 .780,21$ & $\$ 1.457 .701,97$ & $\$ 1.549 .753,87$ \\
\hline 3 & Reino Unidi & $\$ 2.231 .576,78$ & $\$ 1.795 .558,25$ & $\$ 1.836 .245,10$ & $\$ 1.433 .925,61$ & $\$ 1.459 .580,28$ & $\$ 1.533 .574,20$ \\
\hline 4 & Luxemburg & $\$ \quad 588.157,56$ & \$ 587.777,99 & $\$ 567.321,25$ & $\$ 456.132,60$ & $\$ 379.289,72$ & $\$ 435.425,86$ \\
\hline 5 & Alemania & $\$ \quad 578.016,37$ & \$ $494.497,32$ & $\$ \quad 472.165,19$ & $\$ \quad 427.781,91$ & $\$ 409.710,67$ & $\$ 425.643,57$ \\
\hline 6 & Jersey & $\$ \quad 512.129,27$ & $\$ 544.082,58$ & $\$ 474.577,60$ & $\$ 367.103,26$ & $\$ 367.715,64$ & \$ 393.221,52 \\
\hline 7 & Países Baic & $\$ 436.626,68$ & $\$ 413.026,92$ & $\$ 373.464,71$ & $\$ 347.574,79$ & $\$ 349.324,10$ & $\$ 315.947,91$ \\
\hline 8 & Irlanda & $\$ \quad 295.018,56$ & \$2 273.390,41 & $\$ 263.708,06$ & $\$ 286.066,87$ & $\$ 285.165,40$ & $\$ 276.409,52$ \\
\hline 9 & Suiza & $\$ 311.338,38$ & $\$ 289.407,31$ & $\$ 328.829,94$ & $\$ 235.166,23$ & $\$ 255.419,23$ & $\$ 273.973,39$ \\
\hline 10 & Hong Kong & $\$ \quad 329.275,49$ & $\$ 325.140,86$ & $\$ 405.018,48$ & $\$ 315.974,16$ & $\$ 310.859,98$ & $\$ 267.993,97$ \\
\hline
\end{tabular}

Fuente: Hollingshead, 2010: 1

Estos cálculos concuerdan con los ofrecidos por Palan, et. al. (2013) sobre depósitos y préstamos bancarios destinados y originados respectivamente por paraísos fiscales. Según esta estimación, ambos indicadores habrían pasado de representar el $37-38 \%$ en 1996 al $42-46 \%$ en 2007 del total mundial (véase gráfico 4). Estos autores también ofrecen datos muy significativos sobre el origen de la inversión extranjera directa en China extraídos del Ministerio de Comercio de la República Popular China (MOFCOM). Los datos revelan que entre 2006 y 2007 entre las diez principales jurisdicciones de origen, se encontraban Singapur y las Islas Caimán, y en los dos primeros puestos las Islas Vírgenes Británicas y Hong Kong a significativa 
Peramo, Juan Carlos. Paraísos fiscales, riqueza offshore y evasión fiscal. Una estimación para España (1980-2013).

distancia de la tercera, Corea del Sur (véase tabla 2). Por otro lado, los autores recogen las estimaciones de hedge funds radicados en lo que titulan de Big Four: Bahamas, Bermudas, Islas Vírgenes Británicas e Islas Caimán: de un total de 1,5 billones de dólares que representaría la producción industrial mundial anual, solamente en estos cuatro territorios acumularían aproximadamente la mitad de la misma (véase tabla 3). Otras estimaciones como la Merril Lynch/CapGemini estimaban, exclusivamente para high-net worth individuals (HNWI) para el año 1997, 5,8 billones de dólares o las llevadas a cabo por parte del FMI y Oxfam Intermon, que para el año 2000, calculaban 1,7 billones y entre 6 (Henry, 2012: 17-18) y 7 billones de dólares respectivamente (Oxfam, 2000). Debido a la antigüedad de los estudios y la ausencia de detalles en la metodología, su ampliación en el presente trabajo ha sido descartada ${ }^{3}$.

\section{Gráfico 4}

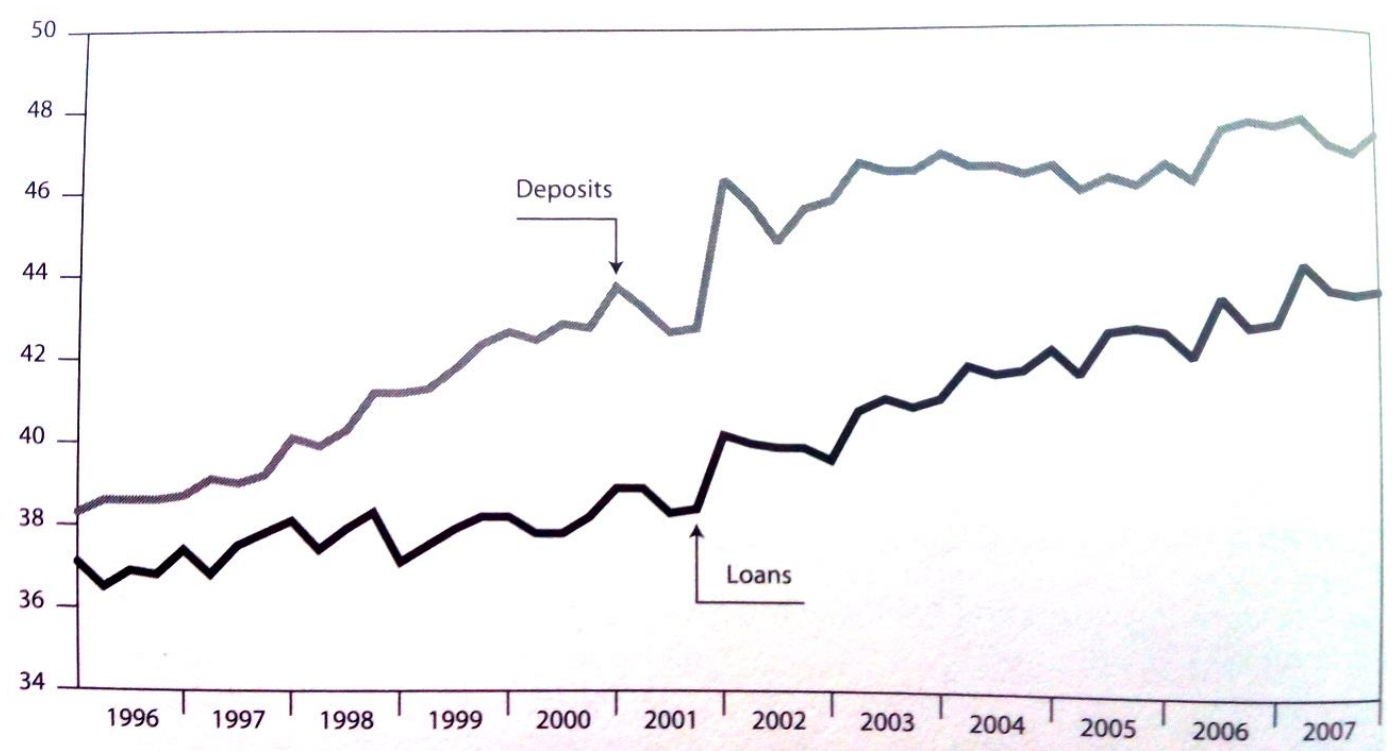

Fig. 2.2 Share of international loans directed to and originating from tax havens and OFCs as percentage of world total. Source: BIS, 2008.

Fuente: Palan et. al., 2013: 52

\footnotetext{
${ }^{3}$ En su informe, la ONG afirma: "Recent estimates put the amount held in offshore centres at between US\$6 and US\$7 trillion, which is approximately equivalent to the annual world trade in goods and services or about one third of total global GDP. Much of this, perhaps between US\$3 and US\$4 trillion, consists of savings held abroad by wealthy individuals" (Oxfam, 2000: 3), sin embargo no mencionan a qué estudios hacen referencia.
} 
Peramo, Juan Carlos. Paraísos fiscales, riqueza offshore y evasión fiscal. Una estimación para España (1980-2013).

Tabla 2

Tabla 210 principales fuentes de IED en China (en miles de millones c

\begin{tabular}{|l|r|r|r|}
\hline Jurisdicción & & 2006 & 2007 \\
\hline Hong Kong & $\$$ & 21,31 & 27,7 \\
\hline Islas Vírgenes Británicas & $\$$ & 11,68 & 16,55 \\
\hline Corea del Sur & $\$$ & 3,99 & 3,68 \\
\hline Japón & $\$$ & 4,76 & 3,58 \\
\hline Singapur & $\$$ & 2,46 & 3,18 \\
\hline Estados Unidos & $\$$ & 3,00 & 2,62 \\
\hline Islas Caimán & $\$$ & 2,13 & 2,57 \\
\hline Samoa & $\$$ & 1,62 & 2,17 \\
\hline Taiwán & $\$$ & 2,23 & 1,77 \\
\hline Mauricio & $\$$ & 1,11 & 1,33 \\
\hline Fuente: MOFCOM & & & \\
\hline
\end{tabular}

Fuente: Palan et. al., 2013: 54

Tablas 3

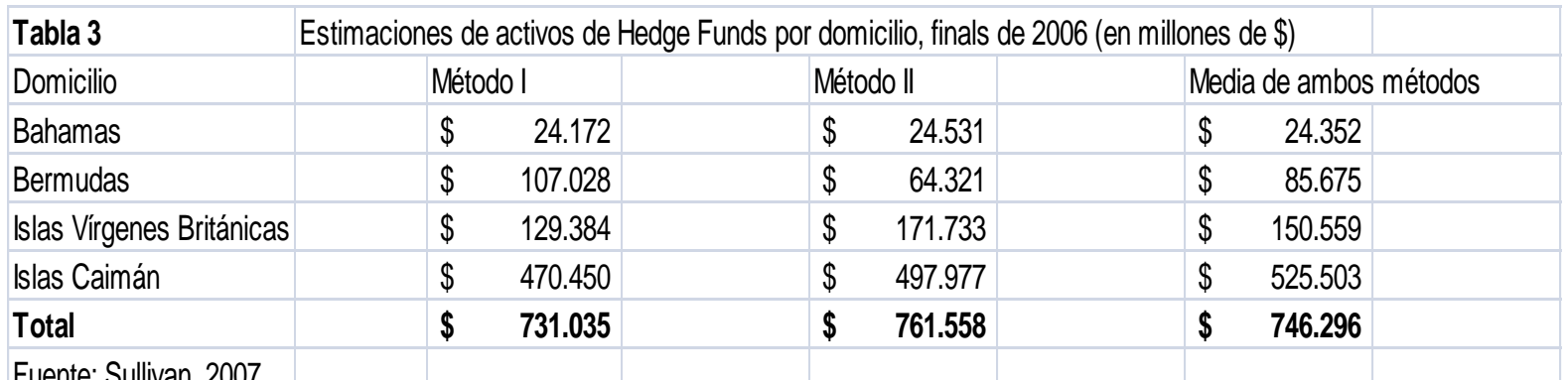

Fuente: Palan et. al., 2013: 61

Las tres estimaciones seleccionadas para su análisis, debido a su relevancia, profundidad y reciente publicación son las disponibles en Henry, (2012); BCG, (2001 2014) y Zucman, (2013a, 2013b, 2014). En cuanto a los resultados que arrojan, Zucman calcula para 2013 que 7,6 billones de dólares (un 8\% de la riqueza financiera mundial) se encuentran en paraísos fiscales. Para ese mismo año, la consultora Boston Consulting Group (BCG) señala que son 8,9 billones de dólares la cantidad que representa la riqueza offshore a nivel mundial (2014), mientras que Henry (2012) calcula 32 billones $^{4}$ de dólares en total a partir de cuatro estimaciones complementarias. A continuación analizaremos la metodología utilizada por cada una de estas estimaciones, así como sus resultados.

\subsection{Estimación de Henry}

Henry en su informe de la Tax Justice Network ${ }^{5}$, enfoca el problema de la riqueza offshore como un "agujero negro" en el cosmos de la riqueza mundial al que, al igual que hacen los astrónomos, hay que acercarse al él con métodos indirectos y precaución, debido a la peligrosidad que confiere a los que se acercan demasiado para observarlos (Henry, 2012: 3). Su objetivo "is not pseudo-precision, much less "really big numbers", but a plausible "base case" for this otherwise-well hidden sector of the global economy" (ibíd.: 4). El estudio es un verdadero intento de estimar la

\footnotetext{
${ }^{4}$ Henry, al igual que el resto de autores utilizan los términos "trillion" y "billions" para referirse a un millón de millones. En el presente trabajo se utilizará la palabra billón y miles de millones.

${ }^{5}$ Se trata de una revisión y ampliación de la estimación realizada en 2005 (TJN, 2005).
} 
Peramo, Juan Carlos. Paraísos fiscales, riqueza offshore y evasión fiscal. Una estimación para España (1980-2013).

riqueza oculta a nivel mundial partiendo de datos públicos, en el marco de una investigación de un "caso base", una estimación al a baja abierta a aportaciones y al escrutinio público.

Para estimar la riqueza evadida a nivel mundial, utiliza cuatro estimaciones distintas enfocándolas desde ángulos diferentes a partir de cuatro métodos: un modelo de fuentes y usos de los flujos de capital sin registrar país por país; un modelo de "riqueza acumulada offshore", estimaciones directas de activos offshore bajo gestión de los cincuenta principales bancos privados del mundo y un modelo de cartera de inversores offshore. Además completa el estudio con evidencia complementaria: la problemática de la alteración de los precios de transferencia; datos de demanda de dinero líquido transfronterizo, plausible de ser trasladado a mercados offshore como reservas de divisas y oro; así como una revisión de investigaciones de mercado por parte de firmas de consultoría sobre el tamaño del mercado de banca privada offshore. No obstante, como hemos señalado anteriormente, estas estimaciones complementarias no forman parte del propósito del presente trabajo.

A continuación se explica en detalle cada uno de los métodos empleados y los resultados posteriores.

\subsubsection{Flujos de capital sin registrar país por país: fuentes y usos}

A partir de datos del Banco Mundial y del FMI, el autor calcula la diferencia entre las mediciones de las fuentes de capital extranjero (préstamos extranjeros, inversión extranjera directa neta e inversiones en cartera) con los usos registrados (incluyendo déficit por cuenta corriente y aumento de las reservas) para 139 países de ingreso medio y bajo a lo largo de 40 años (entre 1970 y 2010). De esta manera, las diferencias existentes contabilizarían por 6,1 billones de $\$$ reales del 2000 (véase tabla 4) se atribuirían a salidas netas de capital sin registrar, y los errores se minimizarían al incluirse una muestra tan amplia (Henry, 2012: 27-28).

\subsubsection{Riqueza acumulada offshore}

Por otra parte, a partir de los cálculos existentes sobre fuga de capitales, Henry estima las ganancias generadas offshore entre 1970 y 2010, partiendo de varios supuestos (ibíd.: 29-30). En primer lugar, que entre el 50 y el $75 \%$ se trata de riqueza cuyos rendimientos no se repatrían, si no que se mantiene offshore invertidos en una cartera relativamente segura de activos denominados en dólares y euros, y principalmente en depósitos a seis meses al tipo de interés medio anual estadounidense en los certificados de depósito. Esto permitiría establecer una estimación conservadora. Por otro lado, el autor supone que el $100 \%$ de las salidas de capital están sin declarar: "otherwise they presumably would not be "unrecorded". (ibíd.: 30). 
Peramo, Juan Carlos. Paraísos fiscales, riqueza offshore y evasión fiscal. Una estimación para España (1980-2013).

Tabla 4

Tabla 4 Ganancias acumuladas offshore reales vs fugas de capital reales acumuladas (Por región, 1970-2010) $\sum$ millones de $\$$ reales del 2000

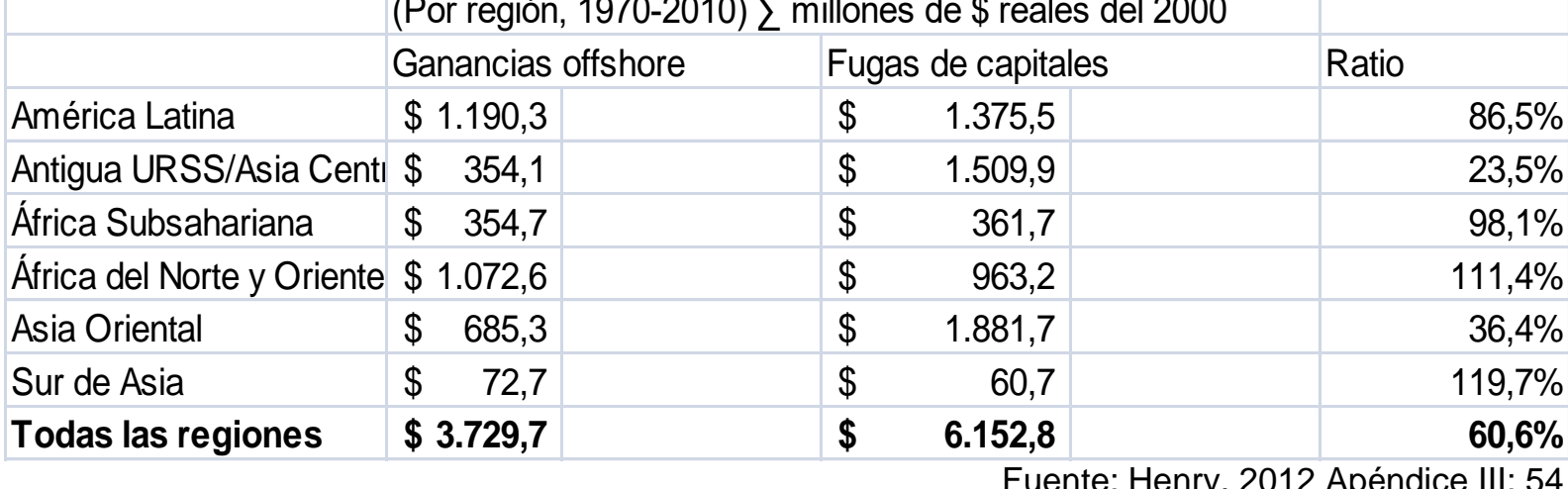

El autor reconoce una limitación de este modelo: el round-tripping. Es decir, que mucha de esa fuga de capitales se estaría contabilizando doblemente, en el país de origen real, y en el paraíso fiscal que sirve de plataforma. El caso de China y Hong Kong, le sirve para establecer un porcentaje aproximado que anule el efecto de distorsión que genera el round-tripping: para China se calcula 743.000 millones de dólares y para Hong Kong 125.900 millones de dólares. El porcentaje que no contaría para China y el resto de países con paraísos fiscales cerca (como México, Venezuela o Brasil con el caso de las islas del Caribe) sería el $17 \%$ aproximadamente (ratio fuga de capitales de Hong Kong entre fuga de capitales de China). Sumando la fuga de capitales y los beneficios offshore que generan, los resultados a nivel global arrojan un total de 9,1 billones de dólares reales del 2000 (véase tabla 4).

\subsubsection{Análisis de los activos de la banca privada}

El tercer método que Henry utiliza para estimar la riqueza offshore consiste en analizar las carteras de activos financieros de los cincuenta principales bancos privados que operan a nivel global. La estimación se realiza mediante un análisis de los activos transfronterizos para el período 2005-2010, extrayendo los datos de los informes anuales de cada compañía y los formularios $10 \mathrm{~K}^{6}$; de entrevistas a analistas de inversiones, expertos en banca privada a nivel mundial y observatorios especializados, como "Wealth Briefing News" y "Money Laundering Alert"; así como a partir de un estudio de mercado para la industria. ${ }^{7}$

Los resultados calculan que para 2010, los cincuenta principales bancos privados globales tienen bajo su gestión un total de 12 billones de dólares de riqueza financiera transfronteriza. Comparado con la estimación de 2005 de la TJN (2005) donde se calculaban 5,4 billones de dólares, podemos observar cómo esta se ha más que duplicado pese a los altibajos de la economía real. Además, según el autor habría que incluir determinados depósitos bancarios y activos de corretaje que no

\footnotetext{
${ }^{6}$ Se tratan de informes anuales a entregar a la U.S. Securities and Exchange Comission, que ofrecen una visión global de la situación empresarial y financiera de la empresa, e incluye los estados financieros auditados. Fuente: http://www.sec.gov/answers/form10k.htm

${ }^{7}$ No sabemos si el autor se refiere al estudio de Euromoney citado anteriormente en el informe, el cual sostenía en 2008 que la industria de la banca privada global tenia activos bajo su gestión por un total de 11,8 billones de dólares:

http://www.euromoney.com/Article/2093990/Private-banking-Methodology.html
}

Papeles de Europa 
Peramo, Juan Carlos. Paraísos fiscales, riqueza offshore y evasión fiscal. Una estimación para España (1980-2013).

estarían incluidos en los reportes y añadirían un $25 \%$ adicional a la estimación, que junto a problemas de registros a la baja y de ausencia de datos serían perfectamente consistentes con la estimación final de entre 21 y 32 de billones de dólares.

\subsubsection{Modelo de cartera de inversores offshore}

El último modelo empleado está basado en una combinación de datos del BIS sobre depósitos transfronterizos y otros activos mantenidos por inversores no bancarios junto con el análisis de un conjunto de supuestos sobre carteras hecha por analistas de la industria del patrimonio, así como entrevistas con bancos privados. Todo esto produce una "cartera tipo" que sirve para producir otra estimación para el tamaño de la riqueza offshore.

El modelo es una revisión del método utilizado en la estimación de 2005, el cual consiste en incrementar los datos del BIS sobre los de depósitos offshore de agentes no bancarios multiplicándolos por un ratio de liquidez (todos los activos financieros entre depósitos bancarios), basado en una estimación anual de Merrill Lynch/CapGemini para carteras de alto valor neto. Pero la estimación realizada en 2005 tenía varios errores que el autor considera que subestimaban la magnitud del problema: en primer lugar partía de 2,7 billones de dólares de depósitos offshore según el BIS para 2004 y no de los 4 billones de dólares de los depósitos offshore de agentes no bancarios. Esta cantidad pasaría de 4,7 billones en 2005, a 7,4 billones en 2007 y caería a 7 billones en 2010. En segundo lugar para estimar el total de activos financieros offshore, los autores utilizaron un ratio de liquidez de 3,5 procedente de un informe de la consultora McKinsey. El problema es que incluía depósitos interbancarios y no coincidía con los depósitos de agentes no bancarios mostrados por el BIS. De hecho, el autor señala que Merrill Lynch/CapGemini ha estimado los ratios de liquidez para individuos de alto valor neto con más de un millón de dólares de activos financieros y el valor medio para 1998-2010 fue de 4,6, entre 2004-2005 de 4,9 y solo en los años de crisis financiera como en el 2002 y entre 2008-2009 el ratio bajó a 4. Estos ratios de liquidez fueron cotejados con los reportados por algunos de los bancos más importantes en la gestión de patrimonio transfronteriza (UBS o Credit Suisse) que igualaban o excedían a los anteriores.

Por tanto, el autor calcula un ratio conservador de estimación mínima de 3 y una máxima de 4,5 basándose en los reportados por Merrill Lynch/CapGemini (véase tabla 5). Los resultados arrojan un rango de riqueza financiera offshore de entre 21 y 32 billones con un punto medio de 26 billones de dólares. No obstante, según el autor "these estimates for 2010 exclude other non-financial very important forms of offshore wealth like non-residential real estate, "alternative investments," and collectibles." (Henry, 2012: 36).

\footnotetext{
${ }^{8}$ Según el mismo estudio utilizado para los ratios de liquidez de Merrill Lynch/CapGemini los bienes inmuebles y las inversiones alternativas podrían añadir entre un $25 \%$ y un $38 \%$ a las carteras de riqueza de alto valor neto (ibíd.).
} 
Peramo, Juan Carlos. Paraísos fiscales, riqueza offshore y evasión fiscal. Una estimación para España (1980-2013).

Tabla 5

\begin{tabular}{|c|c|c|c|c|c|c|c|c|c|c|c|c|c|c|c|c|}
\hline \multirow[t]{2}{*}{ Tabla 5} & \multicolumn{7}{|c|}{ Activos financieros offshore - High net worth individuals } & & \multirow[b]{2}{*}{2006} & \multirow[b]{2}{*}{2007} & & \multirow{2}{*}{\multicolumn{2}{|c|}{2008}} & \multirow[b]{2}{*}{2009} & \multirow{2}{*}{\multicolumn{2}{|c|}{2010}} \\
\hline & & & 2002 & & 2004 & & 2005 & & & & & & & & & \\
\hline \multicolumn{2}{|c|}{ BIS Depósitos offshore } & $\$$ & 2,98 & $\$$ & 4,05 & $\$$ & 4,68 & $\$$ & $5,97 \$$ & 7,43 & $\$$ & 6,93 & $\$$ & 6,59 & $\$$ & 7,01 \\
\hline \multicolumn{17}{|c|}{ de agentes no bancarios } \\
\hline \multicolumn{17}{|l|}{ Ratios de liquidez } \\
\hline Mínimo & & & 3,5 & & 3,0 & & 3,0 & & 3,0 & 3,0 & & 3,0 & & 3,0 & & 3,0 \\
\hline \multicolumn{2}{|c|}{ Máximo (MerryLinch/CapGemini) } & & 3,0 & & 5,0 & & 4,9 & & 4,6 & 4,5 & & 3,6 & & 3,8 & & 4,5 \\
\hline \multicolumn{17}{|c|}{ Total Activos financieros } \\
\hline Mínimo & & $\$$ & 10,4 & $\$$ & 12,1 & $\$$ & 14,0 & $\$$ & $17,9 \$$ & 22,3 & $\$$ & 20,8 & $\$$ & 19,8 & $\$$ & 21,0 \\
\hline \multicolumn{2}{|c|}{ Máximo (MerryLinch/CapGemini) } & $\$$ & 8,9 & $\$$ & 20,2 & $\$$ & 22,9 & $\$$ & $27,5 \$$ & 33,4 & $\$$ & 24,9 & $\$$ & 24,7 & $\$$ & 31,5 \\
\hline Media estimada & & $\$$ & 9,7 & $\$$ & 16,2 & $\$$ & 18,5 & $\$$ & $22,7 \$$ & 27,9 & $\$$ & 22,9 & $\$$ & 22,2 & $\$$ & 26,3 \\
\hline
\end{tabular}

El informe de la TJN tuvo gran repercusión mundial, y diversos medios de comunicación se hicieron eco de la estimación y utilizaron las cantidades expuestas para completar distintos reportajes sobre la materia ${ }^{9}$. Pero también recibió algunas críticas: Gordon y Morris (2013: 118) critican el informe por tener un "enfoque de teoría de la conspiración". Para Zucman (2013: 56-58), la estimación de Henry es exagerada, ya que pese a reconocer la transparencia del método y valorar positivamente que se base en estadísticas accesibles para todos, la cifra de 7 billones en 2010 sobrestima el valor de las cuentas corrientes en paraísos fiscales.

Esto se debe a que incluye los depósitos legítimos que una empresa determinada pueda tener en un estado distinto al de origen, simplemente porque en él tenga operaciones. Es decir, los datos extraídos de depósitos offshore del BIS no nos detallan qué parte de los 7 billones de dólares pertenece a potenciales defraudadores. Para superar esta limitación, Zucman propone un método más riguroso cruzando los datos publicados por los bancos centrales, el cual analizaremos más adelante.

Bajo mi punto de vista, una de las carencias del estudio es la imposibilidad de acceder a los datos y los cálculos en detalle. Pese a que el autor confirma la transparencia del estudio y que este se encuentra abierto al escrutinio público, la realidad es que la metodología solamente se encuentra detallada en el apéndice con gráficos y tablas. Zucman, por otro lado sí que incorpora un apéndice on-line donde es posible consultar dato por dato el producto de sus investigaciones ${ }^{10}$. Además, Henry parte de la suposición de que toda la riqueza offshore está sin declarar y la diferencia entre fuga de capitales y riqueza radicada offshore queda difuminada. Por último, el hecho de que presente sus estimaciones en dólares reales del 2000 puede distorsionar la magnitud del problema. No es necesario conocer la cantidad evadida en un año en términos actuales, ya que las cantidades perdidas tienen más sentido si son expresadas en el valor que tenían en el momento de su evasión.

\footnotetext{
${ }^{9}$ Véase: http://www.bbc.com/news/business-18944097 http://economia.elpais.com/economia/2013/05/27/actualidad/1369618531_171449.html ${ }^{10} \mathrm{http}: / /$ gabriel-zucman.eu
} 
Peramo, Juan Carlos. Paraísos fiscales, riqueza offshore y evasión fiscal. Una estimación para España (1980-2013).

\subsection{Estimación de Boston Consulting Group}

Otra de las estimaciones que ofrecen un cálculo de la riqueza offshore existente a nivel mundial, parte de las datos ofrecidos por la firma de consultoría internacional Boston Consulting Group, que en su base de datos BCG wealth market-sizing recoge la cantidad de riqueza offshore desglosada por países a partir de datos de la contabilidad nacional y de entrevistas a gestores de patrimonio y clientes. No obstante, esta base de datos es privada y no publicable ${ }^{11}$. Por tanto, los datos que utilizaremos aquí serán extraídos a partir de la información que aparece en los informes públicos anuales "Global Wealth Report" (BCG, 2001-2014), que emite la firma a partir de dicha base de datos.

La metodología que utilizan parte de dos iniciativas: la creación de la base de datos ya mencionada, así como un programa de benchmarking y entrevistas con gestores de patrimonio (ibíd., 2003: 28). La base de datos recoge lo que para ellos significa riqueza, denominada activos bajo gestión que incluiría depósitos en efectivo, fondos de mercados de divisas, acciones gestionadas directa o indirectamente, así como activos onshore y offshore. Excluye la riqueza relacionada con los propios negocios de los inversores, bienes inmuebles y de lujo. Por otra parte el concepto de "riqueza global" refleja los activos bajo gestión a lo largo de todos los hogares de los países incluidos en el análisis (ibíd., 2008: 7). El programa de benchmarking pese a variar ligeramente para cada informe anual sigue un método homogéneo. Por citar un ejemplo, en el que se analizaba la riqueza global para 2008 (ibíd., 2009) se cubren 62 mercados de todo el mundo, representando el $98 \%$ de la riqueza global. El estudio de benchmarking incluye 124 instituciones gestoras de patrimonio y los participantes manejaban a finales de 2008 un total de 5,9 billones de dólares en activos. Para redondear los resultados, el análisis se complementa con 40 entrevistas con expertos en gestión de patrimonio así como 45 consultores de la propia firma.

En cuanto a los resultados a escala global, la primera estimación la encontramos en referencia al año 2003 (ibíd., 2004) cuando la riqueza offshore representaría un total de 5,7 billones de dólares. Tan solo muestran la composición de los países de destino de la riqueza, representando Suiza y Reino Unido casi la mitad de la cantidad total. Para el año 2002 (ibíd., 2003), tan solo se presentaron la composición de origen para la riqueza ubicada en Suiza, diferenciando entre porcentaje de riqueza onshore y de offshore. Debido a la escala y a la desagregación de Europa en varios países en el gráfico, no es posible definir con exactitud las cantidades provenientes de cada zona.

Para el año 2004 no se presenta un gráfico donde se muestren las cantidades, pero en el informe de 2005 (ibíd., 2005: 9) la empresa afirma que existen 85,3 billones de dólares en activos bajo gestión de los cuales un 7,5\% se encuentra ubicado offshore, es decir 6,4 billones de dólares. Para el año 2005 el informe directamente no trata la cuestión de la riqueza offshore (ibíd., 2006). Según la firma, en el año 2006 se produce un incremento, llegando a un total de 6,7 billones de dólares (ibíd., 2007: 13). En este caso el informe solo diferencia por país o conjunto de países de origen de la riqueza, siendo los países del Golfo Pérsico los que más porcentaje

\footnotetext{
${ }^{11}$ Comunicado por e-mail por la firma.
} 
Peramo, Juan Carlos. Paraísos fiscales, riqueza offshore y evasión fiscal. Una estimación para España (1980-2013).

poseen offshore con un $40 \%$, y Japón y Norteamérica los que menos con apenas un $2 \%$. Al igual que para el año 2005, el informe de 2008 no estima ninguna cantidad para el 2007, pero sí que lo hace el del año siguiente (ibíd., 2009: 5). Según este informe, los resultados de 2007 y 2008 arrojan una total de 7,3 y 6,7 billones de dólares respectivamente. Por primera vez, encontramos un gráfico que muestra la riqueza tanto por su origen como por su destino. Destacar el aumento respecto al 2003 de Luxemburgo como región de destino pasando de representar el 11\% al 14\% en detrimento de las Islas del Caribe que pasan de representar el $16 \%$ a un $12 \%$. Suiza y Reino Unido (seguramente debido a la inclusión de Dublín en el conjunto) pasan a representar un $51 \%$. Los datos muestran un fuerte crecimiento de la riqueza offshore a nivel global que pasa a representar 7,4 billones de dólares. En general todas las zonas experimentan un aumento significativo destacando Europa, que aumenta su riqueza offshore en $\mathbf{2 0 0 . 0 0 0 ~ m i l l o n e s ~ d e ~ d o ́ l a r e s ~ p a s a n d o ~ a ~ r e p r e s e n t a r ~}$ el $43 \%$ (frente al $41 \%$ anterior) y África y Oriente Próximo con un aumento de 400.000 dólares pasando a representar un 18\% (frente al 13\% anterior). En cuanto a las zonas de destino, las que más notan el incremento global son principalmente Suiza, Reino Unido, las Islas del Canal, y Dublín, y Estados Unidos. El resto se mantiene y solo Luxemburgo desciende (100.000 millones de dólares).

En 2010 la riqueza offshore global vuelve a incrementarse hasta un total de 7,8 billones de dólares. Europa y Norteamérica se mantienen y el resto de zonas aumentan la cantidad de riqueza poseída offshore. En cuanto a las regiones receptoras, Suiza y Estados Unidos vuelven a aumentar los activos gestionados en su territorio, así como Hong Kong y Singapur. Por otro lado, Luxemburgo sigue cayendo, esta vez 200.000 millones de dólares. Para 2011 la riqueza offshore se mantiene en 7,8 billones de dólares. La participación de Europa cae en detrimento de Asia-Pacífico, Oriente próximo y África. Hong Kong y Singapur siguen aumentado su participación llegando a representar 1 billón y Luxemburgo sigue cayendo, llegando a 500.000 millones de dólares de activos offshore gestionados. Estados Unidos por primera vez cae, volviendo a gestionar 600.000 millones de dólares. En 2012 la riqueza offshore se dispara hasta los 8,5 billones de dólares. Todas las zonas de origen de los activos aumentan su riqueza erradicada offshore, excepto

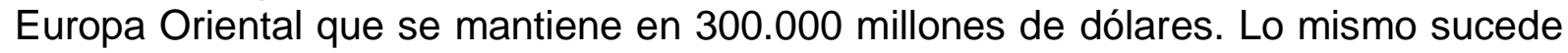
con las zonas de destino (destacar el aumento en 200.000 millones de dólares de Hong Kong y Singapur) exceptuando Reino Unido que se mantiene en 900.000 millones de dólares. Por último, en 2013 podemos observar un aumento significativo de nuevo con un total de 8,9 billones de dólares (ibíd., 2014). Europa Occidental vuelve a caer a 2,6 billones de dólares y el resto de zonas aumentan, sobre todo Asia-Pacífico que vuelve a aumentar su riqueza radicada offshore esta vez en 300.000 millones de dólares (respecto a los 200.000 que aumentó el año anterior). En cuanto a las regiones de destino, todas aumentan su recepción (Hong Kong y Singapur en 200.000 millones de dólares) exceptuando Luxemburgo, Estados Unidos y las Islas del Canal junto a Dublín (por primera vez superadas por las Islas del Caribe) que se mantienen.

Por tanto, podemos observar un crecimiento constante en el periodo 2003-2013 de la riqueza offshore global. Mientras que las regiones de origen más desarrolladas (Europa y Norteamérica) se mantienen constantes durante el periodo, el resto aumentan significativamente, sobre todo la región de Asia-Pacífico, probablemente debido al crecimiento de China. En cuanto a las zonas de destino, Suiza se mantiene la región más receptora de riqueza, Reino Unido y las Islas del Canal, 
Peramo, Juan Carlos. Paraísos fiscales, riqueza offshore y evasión fiscal. Una estimación para España (1980-2013).

disparan su crecimiento en la primera mitad del periodo y Hong Kong y Singapur en la segunda mitad, seguramente influenciado por el crecimiento de la región de origen Asia-Pacífico. Luxemburgo es la zona que más ve caer su recepción ${ }^{12}$ (véanse gráficos 5, 6 y 7$)$.

\section{Gráfico 5}

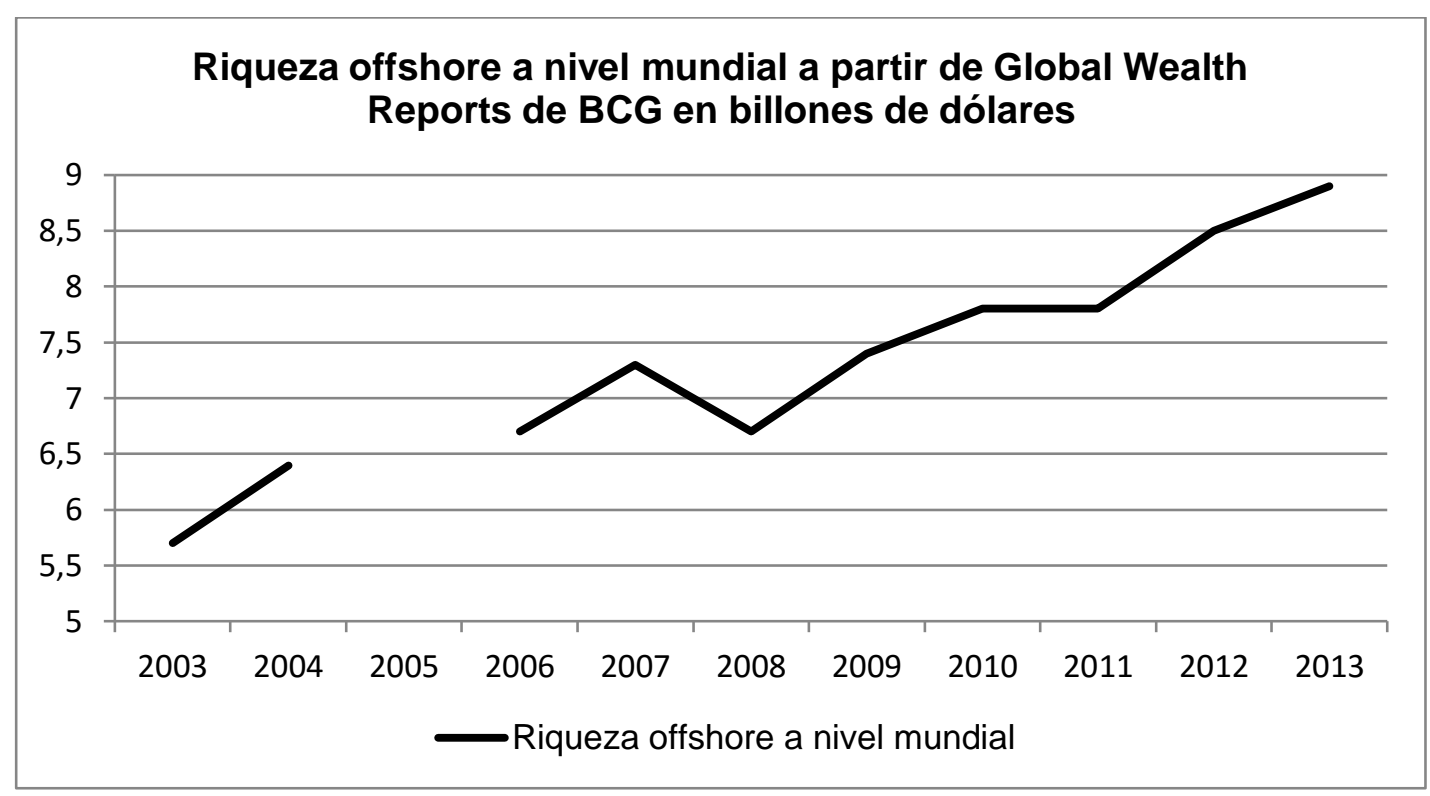

Fuente: Elaboración propia a partir de datos de BCG, 2004 2014. Consúltese la pestaña "BCG - Cálculos" del apéndice electrónico.

\section{Gráfico 6}

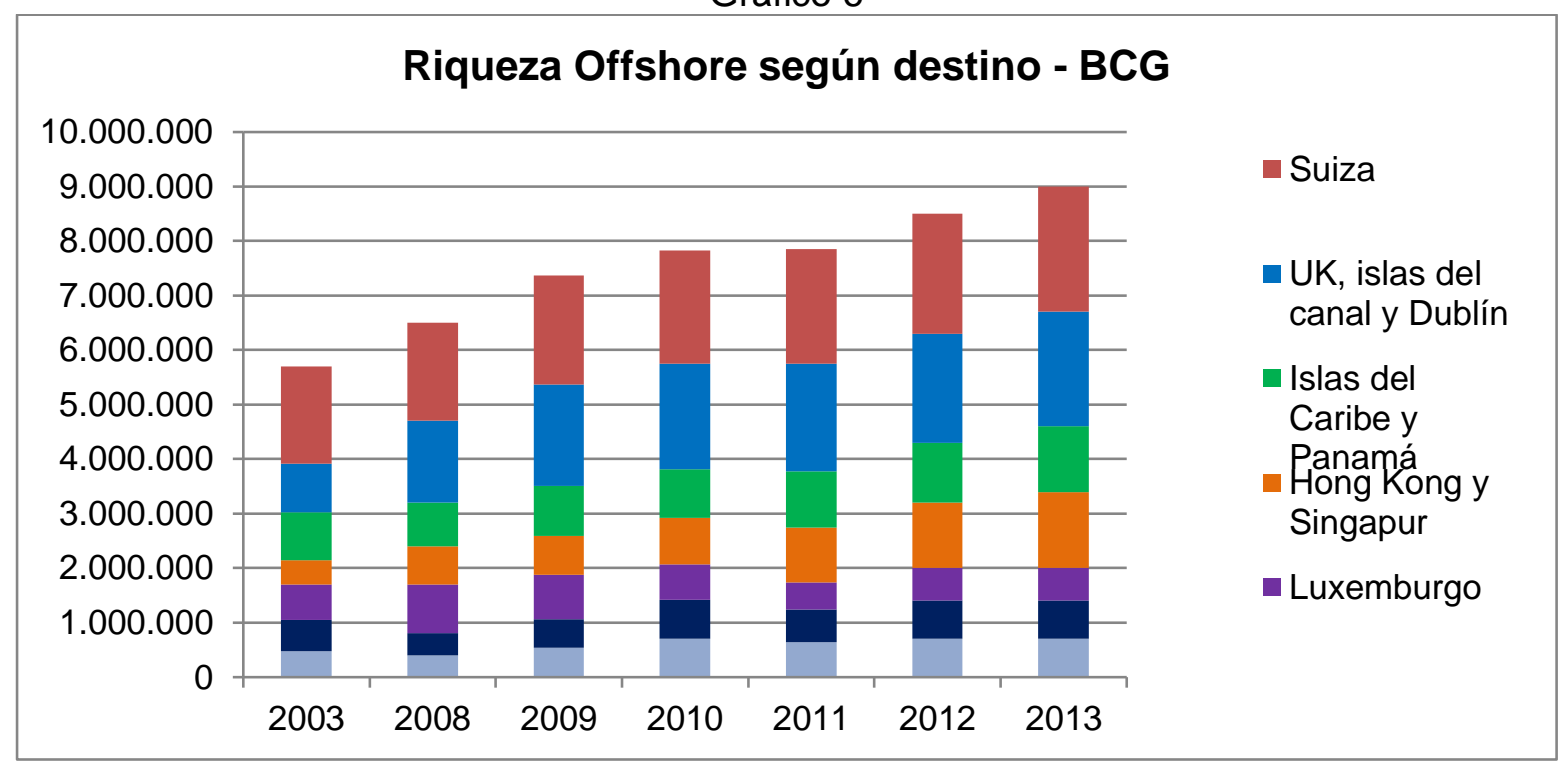

Fuente: Elaboración propia a partir de datos de BCG, 2004 2014. Consúltese la pestaña "BCG - Base datos origen-destino" del apéndice electrónico.

\footnotetext{
${ }^{12}$ Para más detalles, consultar la base de datos creada a partir de los gráficos de BCG, en la pestaña "BCG Base de datos origen-destino" de elaboración propia en el apéndice electrónico complementario al presente trabajo.
} 
Peramo, Juan Carlos. Paraísos fiscales, riqueza offshore y evasión fiscal. Una estimación para España (1980-2013).

\section{Gráfico 7}

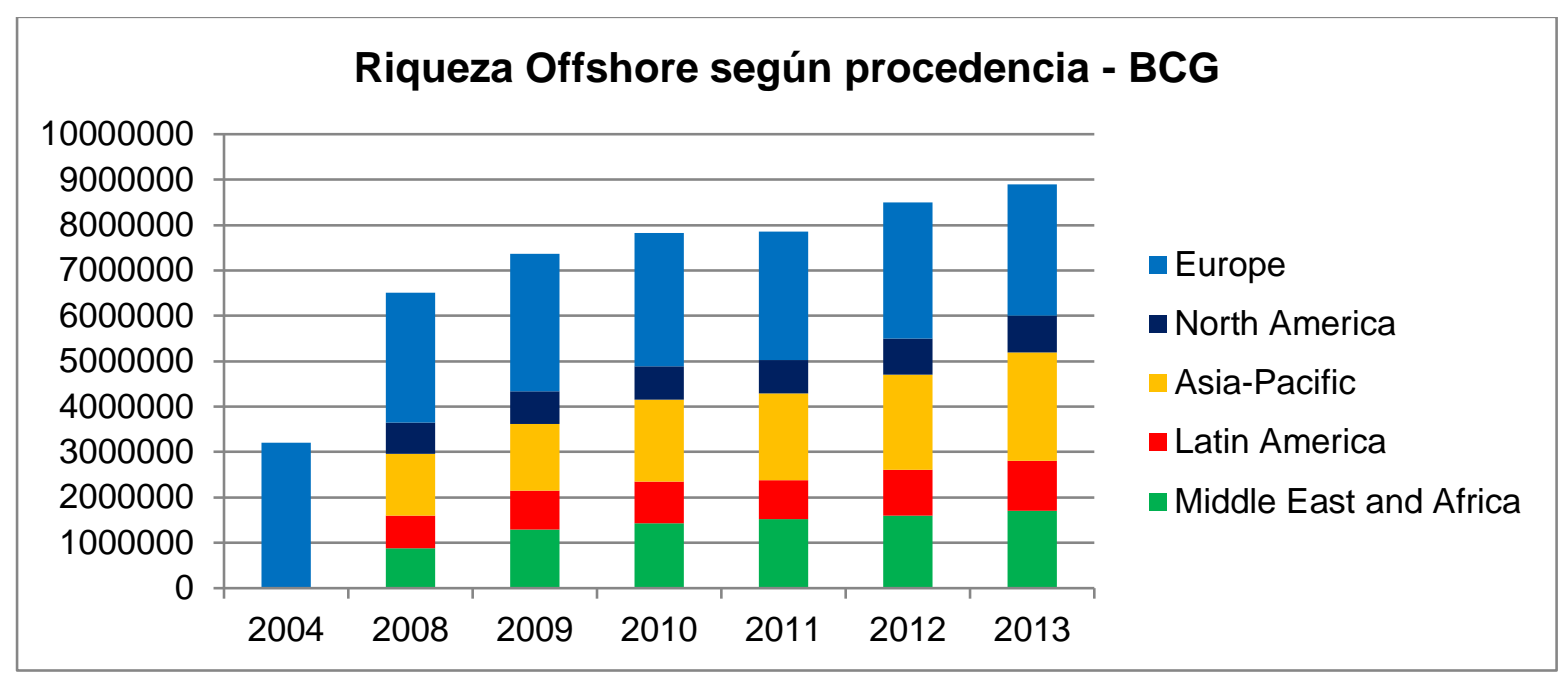

Fuente: Elaboración propia a partir de datos de BCG, 2004 2014. Sin datos previos a 2008, exceptuando 2004 que incluye tan solo Europa. Consúltese la pestaña "BCG - Base datos origendestino” del apéndice electrónico.

Según Henry (2012: 17), las estimaciones de BCG (al igual que las realizadas por otras agencias de consultoría) son ad-hoc y las califica de "imprecisas guesstimates" ya que estarían infravaloradas puesto que, aparte de arrojar resultados inferiores a los calculados por él, omite los pertenecientes a residentes de África ${ }^{13}$ así como todos los activos no financieros en posesión de trusts y fundaciones que suelen ser una parte importante de las carteras de alto valor añadido. No obstante, el problema una vez más es la falta de accesibilidad a la información. La base de datos así como los cálculos y suposiciones que se realizan no son accesibles al escrutinio público, por lo que la credibilidad de los resultados queda supeditada a la confianza del lector en la firma. Por otro lado, la consultora ofrece la siguiente definición de riqueza offshore: "defined as assets booked in a country where the investor has no legal residence or tax domicile" (BCG, 2011: 13) Esta definición denotaría que toda transacción fuera de las fronteras del país de residencia es offshore, y supone una contradicción cuando en sus estimaciones están mostrando resultados en países considerados por la mayoría de listas internacionales paraísos fiscales y excluyendo, evidentemente, los activos que un residente español pueda tener registrados en Francia.

\subsection{Estimación de Zucman}

La estimación de Zucman (2013a, 2013b) sobre riqueza offshore existente a nivel global se trata de una de las más fiables hasta la fecha, debido a la prudencia de sus cálculos, y a que está basada al $100 \%$ en datos públicos. Es decir no parte de una base de datos privada y de entrevistas no publicadas con gestores de fondos privados, y se encuentran on-line accesibles al público. El autor calcula que el $8 \%$ patrimonio financiero de las familias está guardado en los paraísos fiscales, es decir 5,8 y 5,9 billones de dólares en 2008 y 2013 respectivamente (ibíd., 2013b; 2013a). El porcentaje aumenta hasta el $12 \%$ en el caso de los países pertenecientes a la

\footnotetext{
${ }^{13}$ Hecho que es cierto para el informe de 2009 (BCG, 2009), pero que en otros sí incluye al continente (ibíd., 2010, 2011).
} 
Peramo, Juan Carlos. Paraísos fiscales, riqueza offshore y evasión fiscal. Una estimación para España (1980-2013).

Unión Europea. Además, de ese $8 \%$ tres cuartas partes del mismo se encuentra sin declarar (ibíd., 2013a: 11). Por otro lado, el autor aporta valor al realizar un profundo escrutinio de las cuentas radicadas en Suiza, desagregadas por países y zonas geográficas $^{14}$ (véase gráfico 8 ).

Gráfico 8

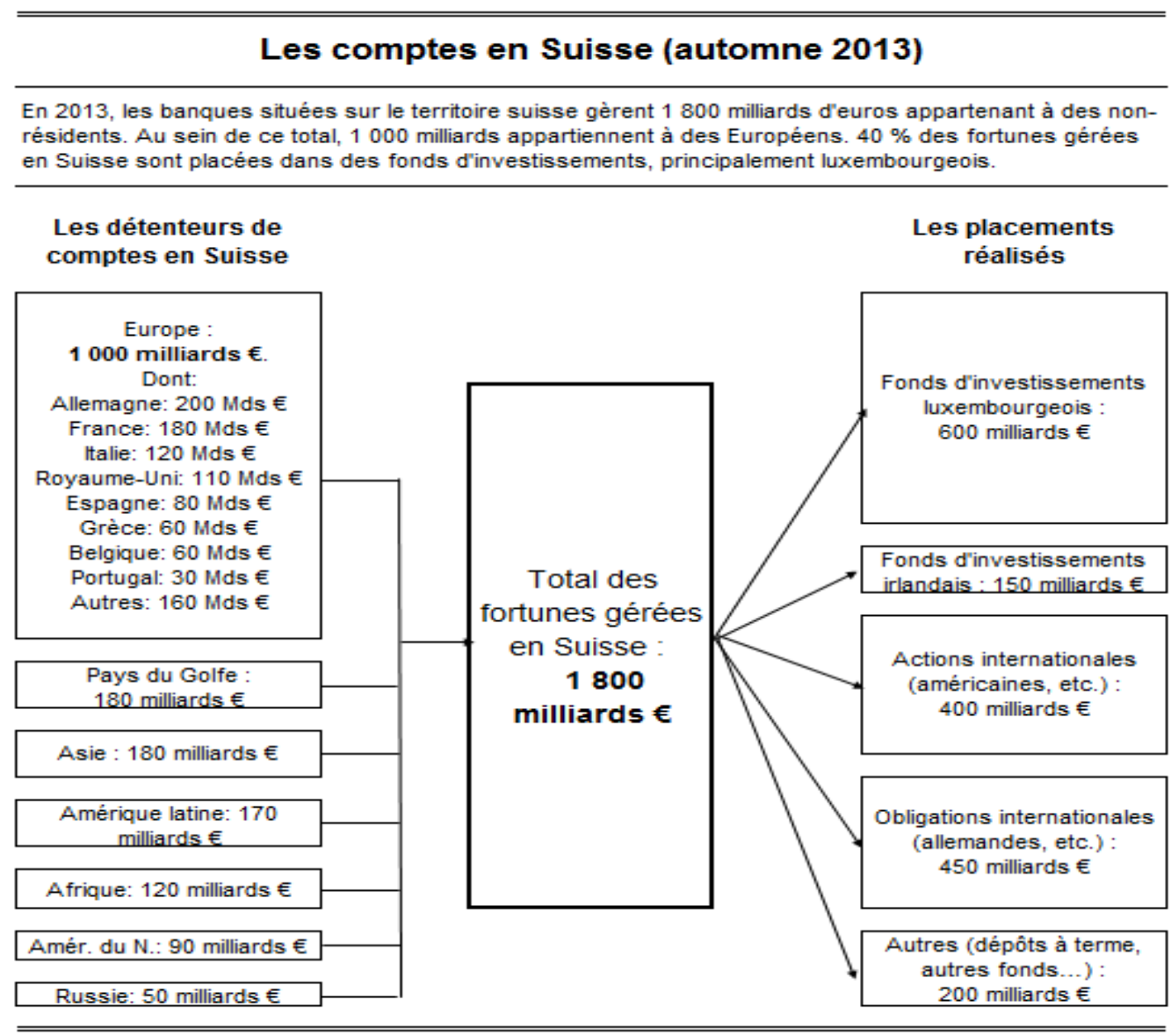

Fuente: Zucman, 2013a

Su estimación parte de dos anomalías presentes en las estadísticas mundiales sobre inversión. En primer lugar, según estas los pasivos exceden a los activos. De manera que el mundo aparece como un deudor neto en su conjunto. Además la balanza de pagos global muestra como se paga más intereses procedentes de la inversión de los que se cobran. Para llevar a cabo el cálculo, el autor suma todas las inversiones en cartera (bonos, acciones y depósitos) a nivel mundial registradas como activo en la zona de residencia del comprador y como pasivo en la zona donde se ha emitido el título. La diferencia entre la agregación de los activos y los pasivos es la cantidad estimada de riqueza financiera sin registrar a nivel global (véase gráfico 9). La existencia de este gap se debe a que si un residente en Francia posee acciones en una cuenta en Suiza de una empresa de Estados Unidos, las autoridades de Estados Unidos registrarán un pasivo en sus cuentas oficiales, pero las de Francia no registrarán un activo. En el caso de Suiza al no tratarse de un deudor ni un acreedor doméstico, las autoridades no registrarán nada.

\footnotetext{
${ }^{14}$ De hecho, estos cálculos del origen de las cuentas suizas fueron construidos en un trabajo anterior (Zucman, 2011) y son la piedra angular del resto de su obra de la que parten el resto de estimaciones.
} 
Peramo, Juan Carlos. Paraísos fiscales, riqueza offshore y evasión fiscal. Una estimación para España (1980-2013).

\section{Gráfico 9}

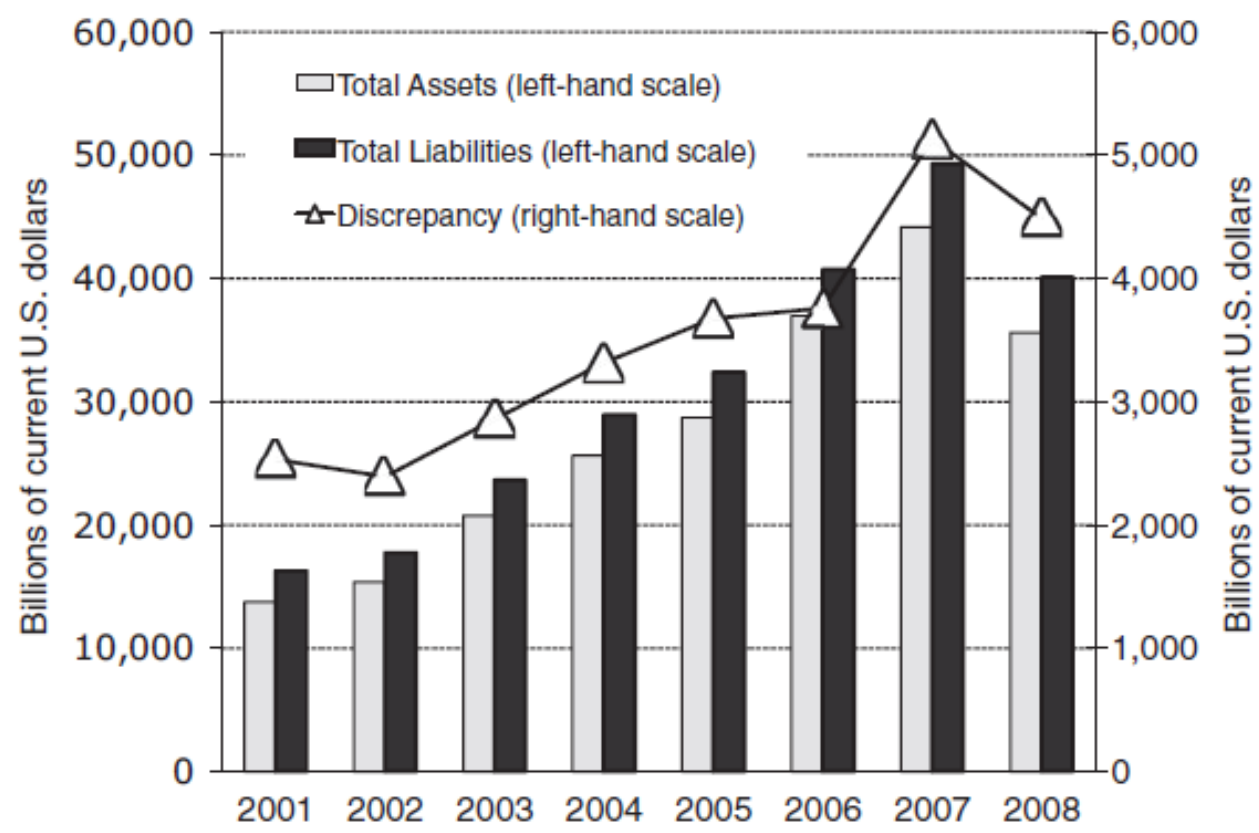

Fuente: Zucman, 2013b: 1342

La principal fuente utilizada para calcular esta diferencia es la base de datos actualizada y extendida "External Wealth of Nations" construida por Lane y MilesiFerretti (2007), a partir de datos de posiciones internacionales de inversión y cubre un total de 178 economías. Después complementa los datos de las zonas no cubiertas con fuentes alternativas y suposiciones ${ }^{15}$ : los países del golfo pérsico, China, Taiwan e Islas Caimán.

Por otro lado, Europa y Estados Unidos, así como otros países desarrollados aparecen en los datos oficiales como deudores netos. El autor rechaza la explicación "China owns the world"16 y apunta a los paraísos fiscales como solución al enigma: "international statistics fail to capture most of the assets held by households through tax havens [...]. This coverage gap explains many of the longstanding anomalies in global data." (Zucman 2013b: 1322). El autor francés calcula que el 8\% de la riqueza financiera mundial está radicada en paraísos fiscales y tres cuartas partes de la misma sin registrar, de manera que el stock total de activos sin registrar representaría el doble de la deuda neta registrada de los países ricos. Esto tendría implicaciones directas en las conclusiones de los estudios que utilizan modelos donde la variable fundamental es la posición neta exterior de los países: Estados Unidos y Europa requerirían de ajustes menores en sus desequilibrios por cuenta corriente. Por tanto, el problema de los países desarrollados estaría dentro de sus fronteras, con unos niveles de desigualdad entre sus habitantes mayores que los registrados oficialmente. Por otro lado, si la posición neta de los países ricos cambiase, debido a la inclusión de las inversiones en cartera radicadas en paraísos fiscales, se podría llegar a la conclusión de que los países en desarrollo están repagando sus deudas a las economías más avanzadas (ibíd.: 1356). La estimación

\footnotetext{
${ }^{15}$ Para completar la cobertura hasta el $99 \%$ utiliza un modelo de posiciones de la cartera a partir de datos provenientes de esos países registrados por Estados Unidos (véase Zucman, 2013b: Tablas A7-A9 del Apéndice).

${ }^{16}$ Para una evaluación crítica sobre este debate véase Nolan, 2012.
} 
Peramo, Juan Carlos. Paraísos fiscales, riqueza offshore y evasión fiscal. Una estimación para España (1980-2013).

solo incluye riqueza financiera, se dejan fuera activos inmuebles, obras de arte y artículos de lujo así como lo que poseen los que residen en paraísos fiscales (ibíd.: 1344). No obstante, la estimación del autor francés parte de dos fuertes supuestos.

En primer lugar, su hipótesis de que aproximadamente tres cuartas partes de las fortunas offshore no están declaradas, basándose en que según las autoridades suizas solo el $20 \%$ de los fondos están declarados vía retención del 35\% por parte de las mismas (ibíd., 2013a: 62) ${ }^{17}$. En segundo lugar, tras realizar una estimación muy rigurosa de la riqueza offshore en Suiza y en el resto de paraísos fiscales (ibíd., 2011 ; 2013b) el autor supone que Suiza representa aproximadamente el $30 \%$ de la riqueza offshore a nivel mundial. En el caso de los países europeos, estima que esa cantidad es el $50 \%$ del total, a partir de datos procedentes del BIS que sugieren que existen la misma cantidad de depósitos bancarios de europeos en Suiza, que en otros paraísos fiscales ${ }^{18}$.

Cruzándolo con los datos presentados por BCG (2004: 18; 2009: 31; 2013: 11) ${ }^{19}$ podemos encontrar una aproximación a las proporciones presentadas por el autor francés: según BCG en 2003, Suiza representaba un 31\% de los activos financieros mundiales radicados offshore, en 2008 un 28\% y en 2012 un 26\%. Además, las fortunas offshore europeas en Suiza tan solo suponen un 35\% respecto al conjunto de paraísos fiscales ${ }^{20}$. La justificación de esta diferencia con el $50 \%$ que calcula Zucman para los activos de los europeos, reside en que como el propio autor afirma, Suiza ha ido modificando su papel en la gestión de activos offshore a nivel mundial, convirtiéndose en vehículo transitorio entre el origen de la riqueza y otros paraísos fiscales (véase gráfico 10). De esta manera tiene sentido que en la base de datos de BCG, Suiza compute tan solo el $35 \%$ de los europeos y cada vez menos en el porcentaje total de la riqueza offshore mundial. ${ }^{21}$

\section{Gráfico 10}

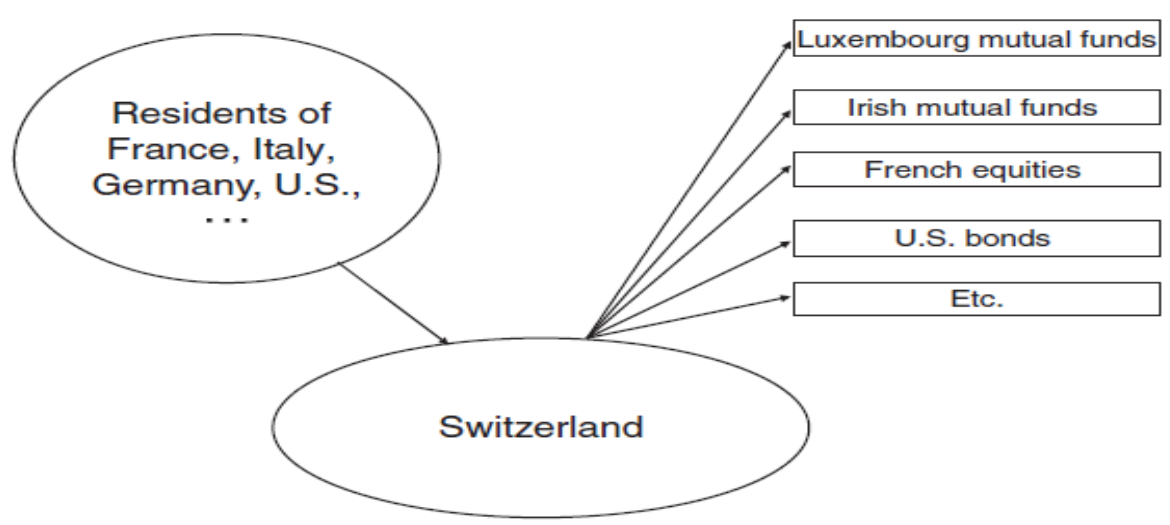

Fuente: Zucman, 2013b: 1331

\footnotetext{
${ }^{17}$ No obstante, acudiendo al apéndice estadístico puede observarse como ese $20 \%$ esta distorsionado por el supuesto de que en los países del Golfo Pérsico el $100 \%$ está declarado, mientras que en el resto del mundo (Europa, Asia América Latina, África, Norteamérica y Rusia) el supuesto es del 10\% declarado. Desconozco la justificación de esa diferencia.

${ }^{18}$ Confirmado por e-mail por el autor.

${ }^{19}$ Véase pestaña "BCG - Suiza" del apéndice electrónico

${ }^{20}$ Véase pestaña "BCG - Base de datos origen-destino" del apéndice electrónico.

${ }^{21}$ En 2008, de los aproximadamente 8.000 fondos registrados en Suiza, 4.600 estaban constituidos en Luxemburgo y 1.200 en Irlanda (Zucman, 2013b: 1330).
} 
Peramo, Juan Carlos. Paraísos fiscales, riqueza offshore y evasión fiscal. Una estimación para España (1980-2013).

Como ha podido observarse en las estimaciones analizadas en el apartado 4, todas ellas calculan un aumento sostenido en el tiempo, tan solo interrumpido debido a la crisis financiera de 2007-2009 22. Además, las cantidades mostradas difieren significativamente. A continuación se presenta una tabla que recoge todas las estimaciones presentadas en el presente trabajo.

Tabla 6

\begin{tabular}{|c|c|c|c|c|c|c|}
\hline Autor & BCG & Zucman & Henry & FMI & $\begin{array}{l}\text { Oxfam } \\
\text { Intermon }\end{array}$ & $\begin{array}{c}\text { Merril } \\
\text { Lynch/CapGem } \\
\text { ini }\end{array}$ \\
\hline Año & 2013 & 2013 & 2012 & 2000 & 2000 & 2000 \\
\hline $\begin{array}{c}\text { Cantidad } \\
\text { estimada } \\
\text { (billones de } \\
\text { dólares) }\end{array}$ & 8,9 & 7,6 & 32 & 1,7 & $6-7$ & 5,8 \\
\hline Metodología & $\begin{array}{l}\text { Base de } \\
\text { datos } \\
\text { propia y } \\
\text { entrevistas }\end{array}$ & $\begin{array}{c}\text { Cruce de } \\
\text { balanzas } \\
\text { de pagos } \\
\text { a nivel } \\
\text { mundial }\end{array}$ & $\begin{array}{l}\text { Cuatro modelos } \\
\text { complementarios }\end{array}$ & Desconocida & Desconocida & $\begin{array}{c}\text { Basada } \\
\text { exclusivamente } \\
\text { en HNWI }\end{array}$ \\
\hline Pública & No & Sí & $\begin{array}{c}\text { Sí (cálculos sin } \\
\text { detallar) }\end{array}$ & No & No & No \\
\hline
\end{tabular}

Fuente: Elaboración propia

\section{ESTIMACIÓN PROPUESTA DE RIQUEZA OFFSHORE Y EVASIÓN FISCAL EN ESPAÑA (1980-2013)}

La existencia de riqueza offshore significa inevitablemente evasión fiscal para las haciendas de los países de residencia de los poseedores. Si toda la riqueza se encontrase en entidades financieras bajo legislación del mismo Estado del que depende la hacienda pública, la información fluiría de manera prácticamente instantánea. Pero el secreto bancario y el dificultoso intercambio de información, no permite a los Estados donde residen los poseedores tener un control 100\% eficaz sobre su patrimonio. Si bien los agentes pueden declarar su riqueza a las autoridades fiscales domésticas por propia iniciativa, (lo cual supondría la legalidad de esta posesión), no toda lo está. Según el criterio de cada autor, el porcentaje de riqueza financiera declarada varía: mientas que para Zucman ésta tan sólo representa un $20-25 \%$, para BCG el porcentaje varía entre un $30 \%$ y un $50 \%$ del total (BCG, 2001: 15). Henry como ya hemos visto, directamente afirma que toda la riqueza offshore que calcula en su informe está sin declarar. Por tanto, la tarea sería cuantificar la cantidad de impuestos que se están dejando de pagar debido a la existencia de paraísos fiscales y del secreto bancario internacional. Para cuantificar la evasión fiscal que supone la existencia de riqueza offshore habría que calcularla en base a la riqueza que no está declarada. No obstante, los autores no incorporan un cálculo sistematizado de la evasión fiscal que supone dicha riqueza offshore. Tan solo Zucman (2013a) incluye en el análisis una estimación de la pérdida fiscal que suponen para las arcas públicas de los países de origen esta riqueza financiera sin declarar. La limitación del análisis para 2013 no permite conocer la cuantía acumulada del problema, ni observar su evolución en el tiempo desde que comenzó

\footnotetext{
${ }^{22}$ Véanse gráficos 3, 5, y 9, así como la tabla 5.
} 
Peramo, Juan Carlos. Paraísos fiscales, riqueza offshore y evasión fiscal. Una estimación para España (1980-2013).

en los años setenta como hemos descrito previamente. En el mismo trabajo, el autor incluye una estimación para el caso de Francia y para el periodo 1970-2013 que cuantifica la cantidad de riqueza offshore y además, permite calcular qué ha supuesto en términos de evasión fiscal para el país para un periodo más amplio y que servirá como modelo para cuantificar en el presente trabajo la evasión fiscal para España.

Por tanto, tras presentar las estimaciones a nivel mundial de la riqueza evadida, la propuesta de este trabajo consiste en acotar la escala a una zona geográfica menor con el fin de cuantificar el problema de un modo más preciso. Si bien Zucman incluye en sus cálculos para 2013 la evasión fiscal para España, solo lo hace para ese año y no todos los tipos impositivos medios son correctos, al menos en este caso $^{23}$. La estimación aquí presentada comienza en 1980 debido a que es a partir de 1981 cuando por un lado, Piketty y Zucman (2014) reportan datos anuales de riqueza financiera neta por hogar, puesto que hasta ese año solo una pequeña parte de los residentes tenían que presentar declaraciones de impuestos individuales (Alvaredo y Saez, 2009: 1143), y por otro lado existen estadísticas detalladas sobre el tipo efectivo del impuesto de patrimonio. En el año 1980 se calcula una cantidad "base" que incluiría todo el acumulado hasta la fecha.

La metodología empleada, detallada en el apéndice metodológico y en la pestaña "Cálculos España" del apéndice electrónico, arroja los siguientes resultados: un aumento de la riqueza radicada offshore sostenido en el tiempo exceptuando en el período de crisis (2008-2009), que llega a superar los 140.000 millones de euros en 2013 (véase gráfico 11).

Gráfico 11

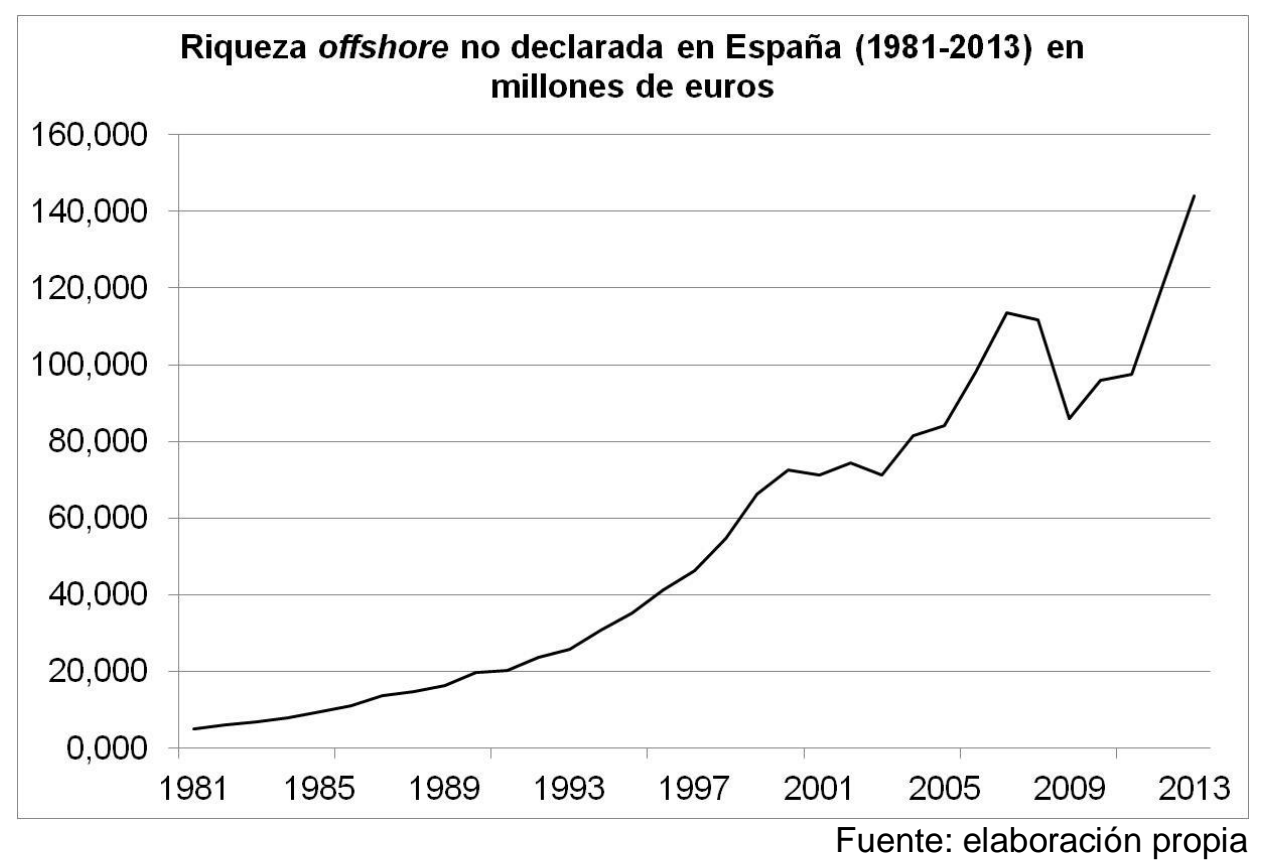

\footnotetext{
${ }^{23} \mathrm{Si}$ bien el impuesto sobre el patrimonio está exento hasta un mínimo y bonificado en algunas comunidades autónomas (http://www.abc.es/economia/20150311/abci-andalucia-cataluna-madrid-irpf-201503102020.html) no se tributa un $0 \%$ a nivel estatal. Además, el factor que el autor aplica a tipo de impuesto de sucesiones y donaciones no tiene en cuenta la tasa de mortalidad del país, ya que aplica un $3 \%$ genérico a todos los países.
} 
Peramo, Juan Carlos. Paraísos fiscales, riqueza offshore y evasión fiscal. Una estimación para España (1980-2013).

Sumando todos los impuestos supuestamente evadidos obtenemos la cantidad total para cada año de evasión fiscal debido al secreto bancario internacional.

Así, la evasión fiscal derivada de la riqueza offshore ascendería para el periodo a más de 116.000 millones de euros, es decir más de un 10\% del PIB de 2013 (véase gráfico 12).

\section{Gráfico 12}

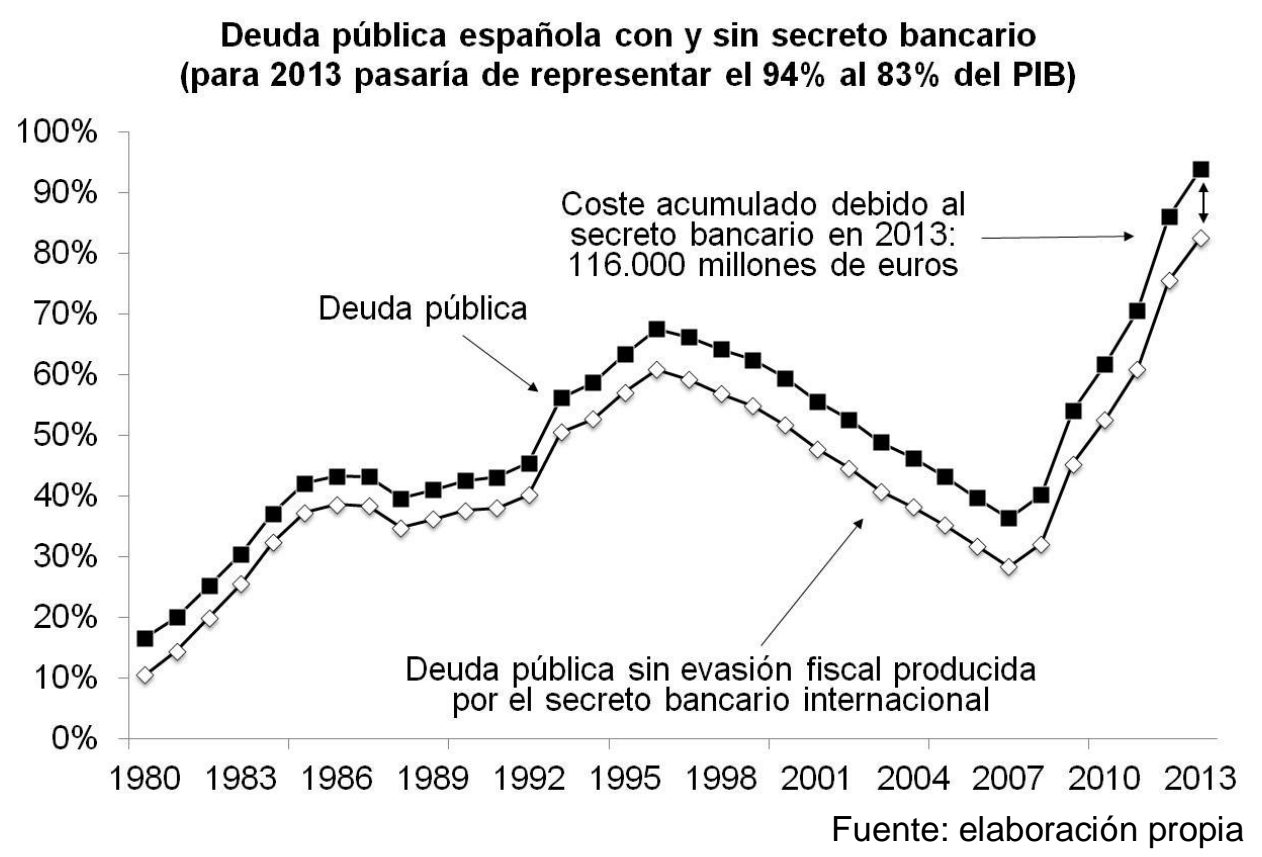

Teniendo en cuenta de que el peso de la deuda pública sobre el PIB para ese mismo año es del 94\%, eliminando hipotéticamente el secreto bancario relacionado con los paraísos fiscales y calculando los intereses que no se habrían pagado, con el consecuente ahorro, esta se podría haber reducido casi una décima parte. Medidas de consolidación fiscal, como las acontecidas en la mayoría de países de la Unión Europea entre 2008 y 2012 (véase Avram et. al., 2013) podrían haberse reducido significativamente. Esto habría tenido un impacto notable en el poder adquisitivo de las familias y empresas, repercutiendo en la actividad económica y en el coste de la deuda pública misma.

\section{CONCLUSIONES}

Por tanto, la información existente relativa a los paraísos fiscales es escasa y heterogénea pese al importante impacto que tienen tanto sobre las economías desarrolladas como las economías en desarrollo, debido a la falta de transparencia e intercambio de información de los agentes económicos residentes. Puede observarse que no existe un consenso a la hora de definir los términos fundamentales para la comprensión del fenómeno y que las fuentes oficiales carecen de estimaciones que cuantifiquen el problema, y si las tienen no son públicas. Tan solo podemos encontrar estimaciones muy dispares tanto en la metodología que emplean como en los resultados que obtienen a la hora de evaluar la cantidad de riqueza radicada en paraísos fiscales. Además la mayoría presentan una falta de transparencia que hace difícil el contraste de su validez. 
Peramo, Juan Carlos. Paraísos fiscales, riqueza offshore y evasión fiscal. Una estimación para España (1980-2013).

No obstante, sí que se puede conocer de manera aproximada la magnitud del problema y que esta ha ido en aumento en los últimos años. Aplicando la metodología de Zucman, a una zona geográfica concreta y en un periodo acotado es posible estimar la riqueza offshore existente cada año. Complementando la estimación con un conjunto de suposiciones y fuentes alternativas, en este trabajo se calcula de manera aproximada, que el secreto bancario existente en los paraísos fiscales ha producido una pérdida de recaudación fiscal para las haciendas públicas de 116.000 millones de euros. De esta manera, puede conocerse el verdadero impacto que los paraísos fiscales tienen en el funcionamiento de la economía y valorar que supone cuantitativamente para los Estados.

La existencia del secreto bancario internacional y la influencia de los paraísos fiscales en las finanzas globales, supone un elemento clave para el desarrollo de la economía mundial. Su eliminación parece una tarea difícil de llevar a cabo debido a la gran influencia que poseen los agentes que se benefician de su funcionamiento. Zucman (2013a) propone un plan de acción en tres fases: la creación de un registro mundial, donde los estados intercambien información de manera automática; el establecimiento de derechos arancelarios y medidas de embargo financiero a los territorios no cooperantes. Para esta parte, es imprescindible la proliferación de nuevas estimaciones que cuantifican el fenómeno, así como la mejora de las ya existentes. Y por último, en una fase más avanzada, el establecimiento de un impuesto global progresivo sobre las fortunas. Solamente mediante la cooperación entre los Estados desarrollados, principalmente Estados Unidos y la Unión Europea, se podría combatir de manera efectiva este problema. 
Peramo, Juan Carlos. Paraísos fiscales, riqueza offshore y evasión fiscal. Una estimación para España (1980-2013).

\section{BIBLIOGRAFÍA}

Alvaredo, F., \& Saez, E. (2009): "Income and wealth concentration in Spain from a historical and fiscal perspective". Journal of the European Economic Association, 7(5), 1140-1167.

Avram, S., Figari, F., Leventi, C., Levy, H., Navicke, J., Matsaganis, M., \& Sutherland, H. (2013): "The distributional effects of fiscal consolidation in nine EU countries" (No. EM2/13). Euromod Working Paper.

Boston Consulting Group, The. (2014): Global Wealth Report 2014: Riding a Wave of Growth.

Boston Consulting Group, The. (2013): Global Wealth Report: Maintaining Momentum in a Complex World.

Boston Consulting Group, The (2012): Global Wealth Report: The Battle to Regain Strength.

Boston Consulting Group, The (2011): Global Wealth Report: Shaping a New Tomorrow. How to Capitalize on the Momentum of Change.

Boston Consulting Group, The (2010): Global Wealth Report: Regaining Lost Ground. Resurgent Markets and New Opportunities.

Boston Consulting Group, The (2009): Global Wealth Reporet: Delivering on the Client Promise.

Boston Consulting Group, The (2008): Global Wealth Report: A Wealth of Opportunities in Turbulent Times.

Boston Consulting Group, The (2007): Global Wealth Report: Tapping Human Assets to Sustain Growth.

Boston Consulting Group, The (2006): Global Wealth Report: Taking the Client's Perspective.

Boston Consulting Group, The (2005): Global Wealth Report: Searching for Profitable Growth.

Boston Consulting Group, The (2004): Global Wealth Report: The Rich Return to Richer Returns.

Boston Consulting Group, The (2003): Global Wealth Report: Winning in a Challenging Market.

Boston Consulting Group, The (2002): Global Wealth Report: Prospering in Uncertain Times.

Boston Consulting Group, The (2001): Global Wealth Report: Richer Prospects in Wealth Management.

Bouvier, J. (1972): "Deux ouvrages du CRISP sur le capitalisme”, Annales. Histoire, Sciences Sociales 27e Année, No. 1 (Jan. - Feb), pp. 93-96.

Chavagneux, C. \& Palan, R. (2007): Los paraísos fiscales. Editorial El Viejo Topo.

Clausing, K. A. (2009): "Multinational firm tax avoidance and tax policy". National Tax Journal, 703-725.

Cobham, A. (2005): "Tax evasion, tax avoidance and development finance". Queen Elizabeth House Working Paper Series, 129.

Comisión Europea (2013): An Action Plan to strengthen the fight against tax fraud and tax evasion, Bruselas.

Comisión Europea (2012): Comunicación de la comisión al Parlamento Europeo y al Consejo. Plan de acción para reforzar la lucha contra el fraude fiscal y la evasión fiscal $\{S W D(2012) 403$ final\} $\{S W D(2012) 404$ final\}. Bruselas.

De la Torre, F. (2014): ¿Hacienda somos todos?: Impuestos y fraude en España. DEBATE. 
Peramo, Juan Carlos. Paraísos fiscales, riqueza offshore y evasión fiscal. Una estimación para España (1980-2013).

Gaggero, J. Rua, M. \& Gaggero, A. (2013): "Argentina: fuga de capitales (20022012)". In Discussion Workshop, City University London, Vol. 20, pp. 20022012.

Garzón, A. (2011): "Paraísos fiscales en la globalización financiera". Historia Actual Online, (26), 141-153.

Gordon, R. K., \& Morriss, A. P. (2013): "Moving Money: International Financial Flows, Taxes, \& Money Laundering". Hastings International and Comparative Law Review, vol. 37.

Henry, J. S. (2012): "The price of offshore revisited". Tax Justice Network. Disponible en:http://www.taxjustice.net/cms/upload/pdf/Price_of_Offshore_Revisited_120 722.pdf (consultado el 1 de Septiembre de 2015).

Hines Jr, J. R., \& Rice, E. M. (1990): "Fiscal paradise: Foreign tax havens and American business" (No. w3477). National Bureau of Economic Research.

Hollingshead, A. (2010): "Privately Held, Non-Resident Deposits in Secrecy Jurisdictions." Global Financial Integrity.

Kar, D., Cartwright-Smith, D., \& Hollingshead, A. (2010): "The Absorption of Illicit Financial Flows from Developing Countries: 2002-2006.", Disponible en SSRN: http://ssrn.com/abstract=2335028 (Consultado el 1 de Enero de 2016).

Karikari, A. G. (2014): "International Tax Avoidance Schemes: An Investigation of Multinational Technology Companies", International Journal of Academic Research in Accounting, Finance and Management Sciences, vol. 4, No. 1, January, 365-370.

Lacalle, D. (2013): "Diez mitos sobre los paraísos fiscales", en Lleno de Energía, disponible en: http://blogs.elconfidencial.com/economia/llenoenergia/2013/04/13/diez-mitos-sobre-los-paraisos-fiscales-8277 (consultado el 1 de Enero de 2016).

Lapavitsas, C. (2011): “Theorizing financialization”. Work, Employment \& Society, 25(4), 611-626.

Lane, P. R., \& Milesi-Ferretti G. M. (2007): "The External Wealth of Nations Mark II: Revised and Extended Estimates of Foreign Assets and Liabilities, 19702004". Journal of International Economics, 73, no. 2, 223-250.

Meister, A. (1975): "Le système transnational/THE TRANSNATIONAL SYSTEM". Civilisations, Vol. 25, No. 1/2, 33-51.

Murphy, R. (2012): "Closing the European tax gap. A report for Group of the Progressive Alliance of Socialists \& Democrats in the European Parliament". Tax Research LLP, disponible en: http://www.socialistsanddemocrats.eu/gpes/media3/documents/3842_EN_rich ard_murphy_eu_tax_gap_en_120229.pdf (consultado el 1 de Enero de 2016). Murphy, R. (2011): "The Cost of Tax Abuse: A Briefing Paper on the Cost of Tax Evasion Worldwide". Tax Justice Network.

Murphy, R. (2005): "Fiscal paradise or tax on development". Tax Justice Network.

Nolan, P. (2012): “Is China buying the world?". Challenge, 55(2), 108-118.

Oxfam Intermon (2015): "La ilusión fiscal". Informe de Oxfam Intermon $n^{\circ} 36$. Disponible

en:https://oxfamintermon.s3.amazonaws.com/sites/default/files/documentos/fil es/InformeLailusionFiscal2015.pdf (consultado el 1 de Septiembre de 2015).

Oxfam Intermon, (2000): 'Tax Havens: Releasing the hidden billions for poverty eradication', briefing paper, Oxford, Junio.

Palan, R., Murphy, R., \& Chavagneux, C. (2013): Tax havens: how globalization really works. Cornell University Press. 
Peramo, Juan Carlos. Paraísos fiscales, riqueza offshore y evasión fiscal. Una estimación para España (1980-2013).

Picciotto, S. (2007): "The International Crisis of Income Taxation: Combating tax havens, capital flight and corruption", Presentation to Critical Legal Conference (Kent, UK), February.

Piketty, T. \& Zucman, G. (2014): "Capital is Back: Wealth-Income Ratios in Rich Countries, 1700-2010". Quarterly Journal of Economics 129(3): 1255-1310.

Piketty, T. (2011): "On the Long-Run Evolution of Inheritance - France 18202050". Quarterly Journal of Economics , vol.61(3), 2011, pp.1071-1131.

Schneider, F. (2012): "Size and development of the Shadow Economy from 2003 to 2012: some new facts". Disponible en: http://www.economics.unilinz.ac.at/members/Schneider/files/publications/2012/ShadEcEurope31.pdf (consultado el 1 de Enero de 2016).

Schuller, H. (1977): Sociétés anonymes, holdings suisses: Impositions, transferts, SA: Allemagne, Belgique, Danemark... les paradis fiscaux. Ed. Sedisa.

Tax Justice Network (2005): "The price of offshore". London: Tax Justice Network. Briefing Paper.

Vigueras, J. H. (2013): "Los paraísos fiscales, plataformas de los mercados financieros". Boletín del Centro de Documentación Hegoa, (36), 1-12.

Vigueras, J. H. (2005): Los paraísos fiscales: cómo los centros "offshore" socavan las democracias. Akal, 2005.

Zoromé, A. (2007): "Concept of offshore financial centers: In search of an operational definition (No. 2007-2087)". International Monetary Fund.

Zucman, G. (2014): "Taxing across borders: Tracking personal wealth and corporate profits". The Journal of Economic Perspectives, 121-148.

Zucman, G. (2014): La riqueza oculta de las naciones. Investigación sobre los paraísos fiscales. Barcelona, Pasado \& Presente, (París, 2013a).

Zucman, G. (2013b): "The Missing Wealth of Nations: Are Europe and the US net Debtors or net Creditors?" The Quarterly journal of economics, 128(3), 13211364.

Zucman, G. (2011): "The missing wealth of nations: Evidence from Switzerland, 1914-2010". Paris School of Economics Working Paper, (2011-07). 